\title{
In Vitro Evaluation of the Toxicological Profile and Oxidative Stress of Relevant Diet-Related Advanced Glycation End Products and Related 1,2-Dicarbonyls
}

\author{
Vanesa Cepas $\mathbb{D}^{1,2}$ Friederike Manig $\mathbb{D},{ }^{3}$ Juan C. Mayo $\mathbb{D}^{1,2}$ Michael Hellwig $\mathbb{D}^{1,4}$ \\ Debora Collotta $\left(\mathbb{D},{ }^{5}\right.$ Valentina Sanmartino, ${ }^{5}$ Rebeca Carrocera-Pumarino ${ }^{D},{ }^{1,2}$ \\ Massimo Collino $\mathbb{D},{ }^{5}$ Thomas Henle $\mathbb{D}^{,},^{3}$ and Rosa $M$. Sainz $\mathbb{D}^{1,2}$ \\ ${ }^{1}$ Departamento de Morfología y Biología Celular, Universidad de Oviedo, Spain \\ ${ }^{2}$ Instituto Universitario de Oncología del Principado de Asturias (IUOPA), Universidad de Oviedo, \\ Instituto de investigación Sanitaria del Principado de Asturias (ISPA), Spain \\ ${ }^{3}$ Chair of Food Chemistry, Technische Universität Dresden, D-01062 Dresden, Germany \\ ${ }_{4}^{4}$ Institute of Food Chemistry, Technische Universität Braunschweig, Schleinitzstraße 20, D-38106 Braunschweig, Germany \\ ${ }^{5}$ Department of Neurosciences 'Rita Levi Montalcini', University of Turin, Italy
}

Correspondence should be addressed to Rosa M. Sainz; sainzrosa@uniovi.es

Received 10 March 2021; Revised 9 May 2021; Accepted 7 July 2021; Published 10 August 2021

Academic Editor: Ana Lloret

Copyright ( 2021 Vanesa Cepas et al. This is an open access article distributed under the Creative Commons Attribution License, which permits unrestricted use, distribution, and reproduction in any medium, provided the original work is properly cited.

During food processing and storage, and in tissues and fluids under physiological conditions, the Maillard reaction occurs. During this reaction, reactive 1,2-dicarbonyl compounds arise as intermediates that undergo further reactions to form advanced glycation end products (AGEs). Diet is the primary source of exogenous AGEs. Endogenously formed AGEs have been proposed as a risk factor in the pathogenesis of diet-related diseases such as diabetes, insulin resistance, cardiovascular diseases, or chronic disease. AGEs may differently contribute to the diet-related exacerbation of oxidative stress, inflammation, and protein modifications. Here, to understand the contribution of each compound, we tested individually, for the first time, the effect of five 1,2-dicarbonyl compounds 3-deoxyglucosone (3-DG), 3-deoxygalactosone (3-DGal), 3,4-dideoxyglucosone-3-ene (3,4-DGE), glyoxal (GO), and methylglyoxal (MGO) and four different glycated amino acids $\mathrm{N}-\varepsilon$-(carboxyethyl)lysine (CEL), $\mathrm{N}-\varepsilon$-(carboxymethyl)lysine (CML), methylglyoxal-derived hydroimidazolone-1 (MG-H1), and pyrraline (Pyrr) in a cell line of human keratinocytes (HaCaT). We found that most of the glycated amino acids, i.e., CEL, CML, and MG-H1, did not show any cytotoxicity. At the same time, 1,2-dicarbonyl compounds 3-DGal, 3,4-DGE, GO, and MGO increased the production of reactive oxygen species and induced cell death. MGO induced cell death by apoptosis, whereas 3-DGal and 3,4-DGE induced nuclear translocation of the proinflammatory NF- $\kappa \mathrm{B}$ transcription pathway, and the activation of the pyroptosis-related NLRP3 inflammasome cascade. Overall, these results demonstrate the higher toxic impact of 1,2-dicarbonyl compounds on mucosal epithelial cells when compared to glycated amino acids and the selective activation of intracellular signaling pathways involved in the crosstalk mechanisms linking oxidative stress to excessive inflammation.

\section{Introduction}

Advanced glycation end products (AGEs) are a heterogeneous group of molecules formed during the Maillard reaction, which is a spontaneous reaction initiated by a nucleophilic addition between the free amino group of a protein, aminophospholipid, or nucleic acid and the carbonyl group of a saccharide $[1,2]$. Protein glycation can occur in vivo in tissues and fluids under physiological conditions. It is a slow and continuous process that drives AGE accumulation in tissues 
during ageing [3]. However, it also takes place ex vivo, during food preparation such as baking, cooking, or frying and during storage [4].

Diet is the main exogenous source of AGEs. It has also been described that AGEs are endogenously produced after a high sugar intake, substantially from fructose [5]. In fact, this high fructose consumption generates an increase in AGE levels in tissue and plasma [6, 7].

RAGE (receptor for AGEs) is a multiligand member of the immunoglobulin superfamily of cell surface molecules that, together with AGER1, AGER2, AGER3 receptors, mediates the biological action of AGEs [8]. Nonetheless, some debate persists over the physiological substrate(s) of RAGE and the validity of several poorly characterized AGE-BSA preparations to serve as models for protein-bound AGEs in the body $[9,10]$. AGEs-RAGE interaction increases ROS formation [11-14], which initiates several signal transduction cascades involving kinases such as P44/P42 MAPK (ERK1/2), PI3K-AKT or P38 MAPK, and NF- $\kappa$ B activation [15-18]. This leads to the production of inflammatory molecules such as cytokines or chemokines that eventually induce inflammation, apoptosis, and proliferation [19-23]. Furthermore, it has been described that AGEs can activate the NLRP3 inflammasome via oxidative stress and inflammation [24, 25].

There is evidence of an existing relationship between endogenous AGE production, AGEs-RAGE interaction, and chronic hyperglycemia [3, 26, 27]. AGE-induced oxidative stress contributes to the most common diabetes-associated complications such as insulin resistance, atherosclerosis, coronary artery disease, endothelial dysfunction [28], and diabetic nephropathy or retinopathy [29-33].

Upon interaction with RAGE, it has been proposed that AGEs increase oxidative stress. An increase in the intracellular levels of $\mathrm{H}_{2} \mathrm{O}_{2}, \mathrm{O}_{2}{ }^{\bullet-}$, and $\mathrm{NO}^{\bullet}$ has been found in endothelial cells $[34,35]$, macrophages [36], and cardiomyocytes [37]. The elevation of oxidative stress upon interaction with RAGE affects mitochondrial function and cell metabolism in various pathological conditions [38, 39].

One of the main challenges to be confronted is that AGEs are a heterogeneous group of different molecules with different chemical structures, and not all of them might exert the same biological effects. Most of the published studies use glycated albumin or a mixture of different AGEs to investigate their biological activities. Since laboratories usually produce these own compounds, the results are sometimes unreliable and difficult to reproduce. In addition, a more detailed study about the individual cytotoxicity of each compound might be of interest.

To solve these drawbacks, we studied the cytotoxicity of nine different compounds, specifically five 1,2-dicarbonyls: 3-deoxyglucosone (3-DG), 3-deoxygalactosone (3-DGal), 3,4-dideoxyglucosone-3-ene (3,4-DGE), glyoxal (GO), and methylglyoxal (MGO); and four glycated amino acids: $\mathrm{N}$ - $\varepsilon$-(carboxyethyl)lysine (CEL), N-E-(carboxymethyl)lysine (CML), methylglyoxal-derived hydroimidazolone-1 (MGH1), and pyrraline (Pyrr) (Figure 1), in a cell model of transformed keratinocytes. The ability to increase oxidative stress, to induce inflammatory pathways, and the type of cell death was investigated.

\section{Material and Methods}

2.1. Glycated Amino Acids and 1,2-Dicarbonyls Synthesis. Test substances for cell assays were synthesized as described beforehand: the dicarbonyls 3-deoxyglucosone (3-DG) [40], 3-deoxygalactosone (3-DGal) [40], and 3,4-dideoxyglucosone-3-ene (3,4-DGE) [41] with Z-3,4-DGE being the predominant form and the glycation compounds pyrraline (Pyrr) [42, 43], N-e-(carboxymethyl)lysine (CML) [44], $\mathrm{N}-\varepsilon$-(carboxyethyl)lysine (CEL) [44], and methylglyoxalderived hydroimidazolone-1 (MG-H1) [44]. Methylglyoxal (MGO) was obtained from Merck KGaA (Darmstadt, Germany) and glyoxal (GO) from Fisher Sci (Madrid, Spain).

2.2. Cell Culture. HaCaT cells (CLS Cell Lines Service) were grown in Dulbecco's Modified Eagle's medium (DMEM) cell culture medium supplemented with $4.5 \mathrm{~g} / \mathrm{L}$ glucose (Merck KGaA, Darmstadt, Germany), $15 \mathrm{mmol} / \mathrm{L}$ 4-(2-hydroxyethyl)-1-piperazineethanesulfonic acid (HEPES) (Merck KGaA, Darmstadt, Germany), 2 mmol/L L-glutamine (Merck KGaA, Darmstadt, Germany), 10\% FBS Merck KGaA (Darmstadt, Germany), and $1 \%$ antibiotic-antimycotic cocktail (Gibco, Thermo Fisher Scientific, Waltham, MA, USA). Cells were cultured at $37^{\circ} \mathrm{C}$ in a humidified $5 \% \mathrm{CO}_{2}$ environment. Cell culture medium was freshly changed every 2 days. Cells were subcultured every 4 days. Briefly, cells were detached using freshly prepared trypsin/EDTA solution (Merck KGaA, Darmstadt, Germany) and incubated at $37^{\circ} \mathrm{C}$ for 10 minutes. Cells were collected by centrifugation at $300 \mathrm{x} g$ for 5 minutes. Finally, cells were seeded at a split ratio of $1: 10$. To perform the experiments, harvested and centrifuged cells were counted using a Neubauer chamber and seeded in cell culture plates at a density of $2.5 \times 10^{4}$ cells $/ \mathrm{mL}$. Cells were always allowed to attach for 48 hours before starting the experiment. Cells were routinely tested for mycoplasma contamination.

2.3. Cell Viability Assay by MTT Reduction. To perform the assay, cells were seeded in 96-well plates in $100 \mu \mathrm{L}$ complete DMEM with $4.5 \mathrm{~g} / \mathrm{L}$ glucose. After 48 hours, cells were incubated with the different compounds to be tested. After 48 hours incubation, $10 \mu \mathrm{L} 5 \mathrm{mg} / \mathrm{mL}$ MTT (Merck KGaA, Darmstadt, Germany) were added to each well and cells were incubated at $37^{\circ} \mathrm{C}$ and $5 \% \mathrm{CO}_{2}$ for 4 hours. Then, $100 \mu \mathrm{L}$ lysis buffer (20\% SDS and 50\% dimethylformamide, pH 4.7) was added to each well, and cells were left in the incubator at $37^{\circ} \mathrm{C}$ and $5 \% \mathrm{CO}_{2}$ overnight [45]. Absorbance was measured at $570 \mathrm{~nm} v s .690 \mathrm{~nm}$ in a Varian Cary 50-MPR UV-Vis spectrophotometer (Agilent Technologies, Santa Clara, CA, USA). Results are shown as the mean of six samples \pm SEM.

2.4. Cell Viability Assay by Trypan Blue Exclusion. The cell death inhibitors were previously dissolved in 100\% dimethyl sulfoxide (DMSO) and then added to culture media from a 1000x stock solution. Therefore, DMSO concentration was never higher than $0.1 \%$, and this concentration was also added to the control group. $2 \mu \mathrm{mol} / \mathrm{L}$ Ferrostatin-1 (0,001\% DMSO) (Cayman Chemical, Ann Arbor, MI, USA), 2 mM 3-methyladenine (0,1\% DMSO) (Cayman Chemical, Ann Arbor, MI, USA), $100 \mu \mathrm{mol} / \mathrm{L}$ Necrostatin-1 (0,001\%) (Cayman Chemical, Ann Arbor, MI, USA), or $10 \mu \mathrm{M}$ 


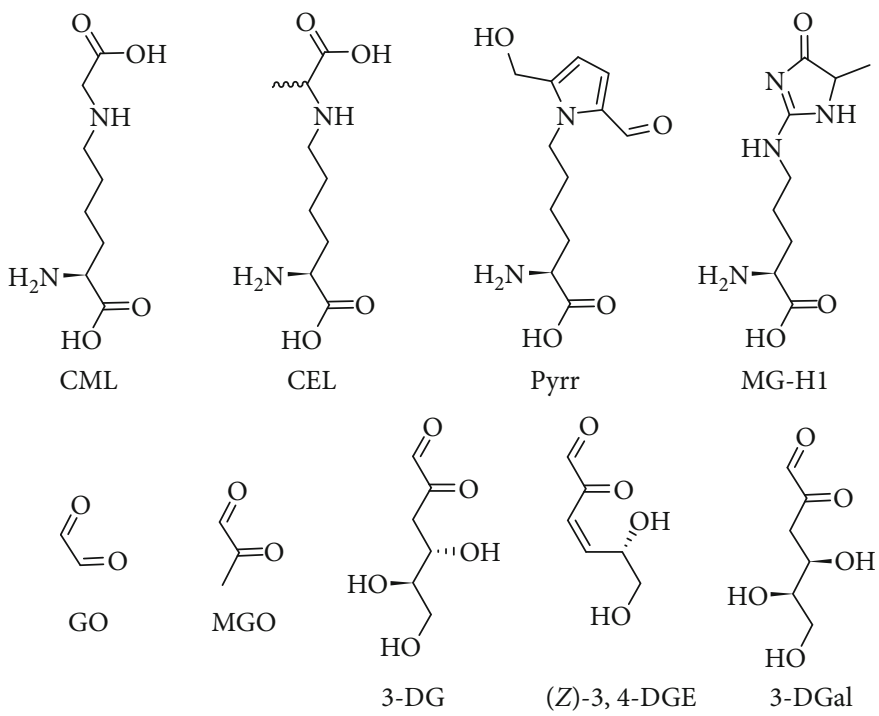

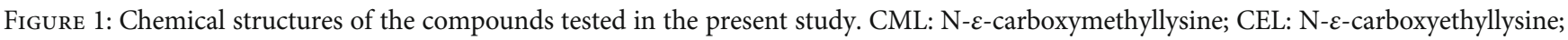
Pyrr: pyrraline; MG-H1: methylglyoxal-derived hydroimidazolone 1; GO: glyoxal; MGO: methylglyoxal; 3-DG: 3-deoxyglucosone; 3,4-DGE: 3,4-dideoxyglucosone-3-ene; 3-DGal: 3-deoxygalactosone.

Quinoline-Val-Asp-Difluorophenoxymethyl Ketone (Q-VD$\mathrm{OPh}$ ) (0,001\% DMSO) (Merck KGaA, Darmstadt, Germany) were employed as inhibitors of ferroptosis, autophagy, necroptosis, and apoptosis, respectively.

To discover the involvement of oxidative stress, $10 \mathrm{mmol} / \mathrm{L}$ N-acetyl-cysteine (NAC) (Merck KGaA, Darmstadt, Germany) was used. This compound was freshly dissolved in a culture medium at pH7.4 and added to the culture media from a $100 \mathrm{mmol} / \mathrm{L}$ stock solution. The culture medium was adjusted to the same volume in each group.

To perform the assay, cells were seeded in 24-well plates containing $500 \mu \mathrm{L}$ complete DMEM with $4.5 \mathrm{~g} / \mathrm{L}$ glucose. After 48 hours, cells were firstly incubated with the corresponding cell death inhibitor or with NAC for 30 minutes in the incubator at $37^{\circ} \mathrm{C}$ and $5 \% \mathrm{CO}_{2}$. Then, the different 1,2-dicarbonyls were added to the culture media. After 48 hours of incubation, cells were detached using trypsin/EDTA solution. Detached and attached cells were collected into the same tube. Cells were stained with $0.4 \%$ trypan blue (Merck KGaA, Darmstadt, Germany) using a dilution 1:1, allowing the mixture to incubate for 3 minutes at RT. Cells were counted using a Neubauer chamber, and the ratio between viable and nonviable cells was calculated. Results are shown as the mean of three samples \pm SEM.

2.5. Cell Cycle Analysis. For cell cycle analysis, cells were seeded in 24-well plates in $500 \mu \mathrm{L}$ complete DMEM with $4.5 \mathrm{~g} / \mathrm{L}$ glucose. After 48 hours, cells were incubated with the different compounds to be tested. After 48 hours of incubation, cells were detached using trypsin/EDTA solution. Detached and attached cells were added and collected into the same tube. Cells were centrifuged at $300 \mathrm{x} g$ for 5 minutes. Cell pellet was washed twice in PBS and centrifuged at $300 \mathrm{xg}$ for 5 minutes. Cells were then fixed in cold $70 \%$ ethanol and left at $4^{\circ} \mathrm{C}$ for at least 30 minutes. After that, cells were washed once in $2 \mathrm{~mL}$ PBS supplemented with $2 \%$ bovine serum albumin (BSA) and centrifuged at $300 \times \mathrm{g}$ for 5 minutes. Then, the cell pellet was resuspended in $500 \mu \mathrm{L}$ propidium iodide (PI)/ribonuclease (RNase) Solution (Immunostep S.L, Salamanca, Spain), mixed well, and incubated for 15 minutes at RT. Finally, cells were analyzed in a BD Accuri ${ }^{\mathrm{TM}}$ C6 flow cytometer (BD Biosciences, San Jose, CA, USA), and data analysis was performed by using BD Accuri ${ }^{\mathrm{TM}}$ C6 Software. At least $10^{4}$ events per sample were analyzed. Results are shown as the mean of three samples \pm SEM.

2.6. Quantification of Intracellular and Mitochondrial ROS Levels. To detect intracellular and mitochondrial ROS production, cells were seeded, treated, and collected as described above. To measure $\mathrm{O}_{2}{ }^{\bullet-}$ production, cells were incubated in $500 \mu \mathrm{L} 5 \mu \mathrm{mol} / \mathrm{L}$ dihydroethidium (DHE) (Bioquochem S.L., Llanera, Spain) for 30 minutes at RT. $\mathrm{H}_{2} \mathrm{O}_{2}$ and $\mathrm{HNO}_{3}{ }^{-}$production was examined by incubating cells in $500 \mu \mathrm{L} 5 \mu \mathrm{mol} / \mathrm{L}$ dihydrorhodamine 123 (DHR-123) (Bioquochem S.L, Llanera, Spain) for 30 minutes at RT. To measure mitochondrial $\mathrm{O}_{2}{ }^{--}$production, cells were incubated with $500 \mu \mathrm{L} 5 \mu \mathrm{mol} / \mathrm{L}$ MitoSOX ${ }^{\mathrm{TM}}$ Red (Invitrogen, Thermo Fisher Scientific, Waltham, MS, USA) for 10 minutes at $37^{\circ} \mathrm{C}$. Finally, cells were analyzed using a BD Accuri ${ }^{\mathrm{TM}}$ C6 flow cytometer (BD Biosciences, San Jose, CA, USA), and data analysis was performed using BD Accuri ${ }^{\mathrm{TM}}$ C6 Software. At least $10^{4}$ events per sample were analyzed. Results are shown as the mean of three samples \pm SEM.

2.7. Annexin-V and 7-AAD Apoptosis Assay. To perform the apoptosis assay, cells were seeded, treated, and collected as described above. Cells were stained using the fluorescein isothiocyanate (FITC) Annexin V Apoptosis Detection Kit with 7-aminoactinomycin D (7-AAD) (Immunostep S.L., Salamanca, Spain) and following the manufacturer's instructions. Briefly, cells were resuspended in $100 \mu \mathrm{L}$ Annexin V binding buffer. Then, $5 \mu \mathrm{L}$ Annexin V-FITC and $5 \mu \mathrm{L} 7$-AAD were 
added, and cells were incubated for 15 minutes at RT in the dark. After that, $400 \mu \mathrm{L}$ Annexin V binding buffer was added to all samples. Finally, cells were analyzed using a BD Accuri ${ }^{\mathrm{TM}}$ C6 flow cytometer (BD Biosciences, San Jose, CA, USA), and data analysis was performed using BD Accuri ${ }^{\mathrm{TM}}$ C6 Software. At least $10^{4}$ events per sample were analyzed. To calculate the percentage of apoptotic cells, Annexin V-FITC positive cells as well as Annexin V-FITC- and 7-AAD-positive cells were considered. Results are shown as the mean of three samples \pm SEM.

2.8. Protein Extraction. For protein extraction, cells were seeded in $100 \mathrm{~mm}$ plates containing $10 \mathrm{~mL}$ of complete DMEM with $4.5 \mathrm{~g} / \mathrm{L}$ glucose. After 48 hours, cells were incubated with the different compounds to be tested. After 48 hours of incubation, cells were detached using trypsin/EDTA solution. Detached and attached cells were collected into the same tube. Cells were centrifuged at $300 \mathrm{x}$ g for 5 minutes. Cell pellet was washed twice in PBS and centrifuged at 300 $\mathrm{x} g$ for 5 minutes. Then, cells were lysed in radioimmunoprecipitation assay (RIPA) lysis buffer $(50 \mathrm{mmol} / \mathrm{L}$ Tris- $\mathrm{HCl}$, $\mathrm{pH} 7.4,150 \mathrm{mmol} / \mathrm{L} \mathrm{NaCl}, 0.1 \%$ sodium dodecyl sulfate (SDS), $1 \%$ Igepal C and $0.5 \%$ sodium deoxycholate) supplemented with freshly added $2 \mu \mathrm{g} / \mathrm{mL}$ aprotinin, $1 \mathrm{mmol} / \mathrm{L}$ dithiothreitol (DTT), $10 \mu \mathrm{g} / \mathrm{mL}$ leupeptin, $1 \mu \mathrm{g} / \mathrm{mL}$ pepstatin, $1 \mathrm{mmol} / \mathrm{L}$ phenylmethylsulfonylfluoride (PMSF), $1 \mathrm{mmol} / \mathrm{L}$ sodium fluoride, and $200 \mu \mathrm{mol} / \mathrm{L}$ sodium orthovanadate for 30 minutes in ice. After incubation, cells were centrifuged at $15,000 \mathrm{x} \mathrm{g}$ for 15 minutes at $4^{\circ} \mathrm{C}$, and the supernatant containing the proteins was transferred to a new tube. Proteins were stored at $-80^{\circ} \mathrm{C}$.

Protein concentration was estimated using the colorimetric Bradford assay [46] (Bioquochem S.L., Llanera, Spain). The absorbance was measured at $595 \mathrm{~nm}$ in a Varian Cary 50-MPR UV-Vis spectrophotometer (Agilent, Santa Clara, CA, USA).

2.9. Western Blot. To perform western blot assay, $30-50 \mu \mathrm{g}$ of proteins were mixed $1: 4$ with loading buffer $(250 \mathrm{mmol} / \mathrm{L}$ Tris-HCl, $40 \%$ glycerol, $8 \%$ SDS, $0.2 \%$ bromophenol blue, and $2.8 \% \quad \beta$-mercaptoethanol). Then, proteins larger than $50 \mathrm{kD}$ were separated in a $10 \%$, and proteins smaller than $50 \mathrm{kD}$ were separated $15 \%$ SDS-polyacrylamide gel electrophoresis (PAGE) using a Mini-PROTEAN ${ }^{\circledR}$ Tetra Vertical Electrophoresis Cell (Bio-Rad, Hercules, CA, USA). Then, proteins were electrotransferred to Immobilon ${ }^{\circledR}$-P polyvinylidene difluoride (PVDF) membranes (Millipore, Merck KGaA, Darmstadt, Germany) using a Mini Trans-Blot ${ }^{\circledR}$ Cell (Bio-Rad, Hercules, CA, USA). After that, the membranes were always stained with Ponceau solution (Bioquochem S.L, Llanera, Spain) to confirm that the proteins were correctly transferred. Then, membranes were incubated with $5 \%$ nonfat dry milk in TBS-Tween buffer (TBS-T, Tris- $\mathrm{HCl}$ $20 \mathrm{mmol} / \mathrm{L}, \mathrm{pH} 7.4,150 \mathrm{mmol} / \mathrm{L} \mathrm{NaCl}, 0.05 \%$ Tween) for 1 hour at RT. After that, membranes were incubated overnight at $4^{\circ} \mathrm{C}$ with the corresponding primary antibody anti- $\alpha$-tubulin ( $1: 2000$, \#ab7291, abcam, Cambridge, UK), anti- $\beta$-actin ( $1: 8000$, \#sc-69879, Santa Cruz Biotechnology, Santa Cruz, CA, USA), anti-catalase $(1: 5000, \# 219010$, Calbiochem,
Merck KGaA, Darmstadt, Germany), anti-gasdermin D ( $1: 1000$, \#93709, Cell signaling, Danvers, MS, USA), anti-I $\kappa \mathrm{B} \alpha$ ( $1: 1000$, \#4814 Cell signaling, Danvers, MS, USA), anti-phospho-I $\kappa \mathrm{B} \alpha$ (Ser32/36) $(1: 1000$, \#9246 Cell signaling, Danvers, MS, USA), anti-IKK $\beta(1: 1000$, \#2370, Cell signaling, Danvers, MS, USA), anti-phospho-IKK $\alpha / \beta$ (Ser176/180) $(1: 1000$, \#2697, Cell signaling, Danvers, MS, USA), anti-NF- $\kappa$ B p65 $(1: 1000$, \#8242, Cell signaling, Danvers, MS, USA), antiNLRP3 (1:1000, \#AG-20B-0014, AdipoGen, Liestal, Switzerland), anti-SOD1 (1:5000, \#574597, Calbiochem, Merck KGaA, Darmstadt, Germany), and anti-SOD2 (1:5000 \#06984, Millipore, Merck, KGaA, Darmstadt, Germany). Primary antibodies were visualized by binding horseradish peroxidase(HRP-) conjugated anti-rabbit (\#12-348, Sigma-Aldrich, Merck KGaA, Darmstadt, Germany), anti-mouse (\#12-349, Sigma-Aldrich, Merck KGaA, Darmstadt, Germany), or antisheep (\#12-342, Sigma-Aldrich, Merck KGaA, Darmstadt, Germany) immunoglobulin $\mathrm{G}$ (IgG) secondary antibodies for 1 hour at RT. Antibodies were further detected with Immobilon ${ }^{\circledR}$ Western Chemiluminescent HRP Substrate (Millipore, Merck KGaA, Darmstadt, Germany). Then, an Amersham Hyperfilm $^{\mathrm{TM}}$ photographic film (Fisher Scientific, Thermo Fisher Scientific, Waltham, MS, USA) was exposed to the membrane and further developed and fixed in a dark room. Blots were all scanned at 300 dots per inch (dpi) grayscale, and densitometry was quantified by the open-source FIJI software. Results are shown as the mean of 3 samples \pm standard error of the mean (SEM).

2.10. Statistical Analysis. Unless otherwise indicated, data are presented as mean \pm standard error of the mean (SEM). Under normal distribution, differences were estimated using student's $t$-test. When samples did not follow a normal distribution, a nonparametric Mann-Whitney $U$ Test was performed. Results were only considered statistically significant if $p<0.05$. Graphs and statistical analysis were done using the Prism 8 software (GraphPad Software, Inc, USA).

\section{Results}

3.1. Most 1,2-Dicarbonyls Were Cytotoxic, whereas Glycated Amino Acids Did Not Alter Cell Viability. As mentioned above, most of the studies published in which the cytotoxicity of AGEs was tested have used albumin glycated by diverse techniques or a solution containing a mixture of different AGEs at unknown concentrations. This, in addition to the many different protocols, makes reproducibility a challenging task. Moreover, to find a relation between the structure and function of these compounds is one of the main aims of this work.

Hence, several synthesized glycated amino acids (CEL, CML, MG-H1, and Pyrr) and 1,2-dicarbonyls (3-DG, 3-DGal, 3,4-DGE, GO, and MGO) were tested on the keratinocyte cell line $\mathrm{HaCaT}$ using a wide concentration range to assay their possible cytotoxicity in cell culture. After attachment, cells were incubated for 48 hours with these compounds, and an MTT viability assay was performed.

Only 1,2-dicarbonyls showed cytotoxicity in cell culture (Figure 2(a)). They displayed a clear dose-response, being 


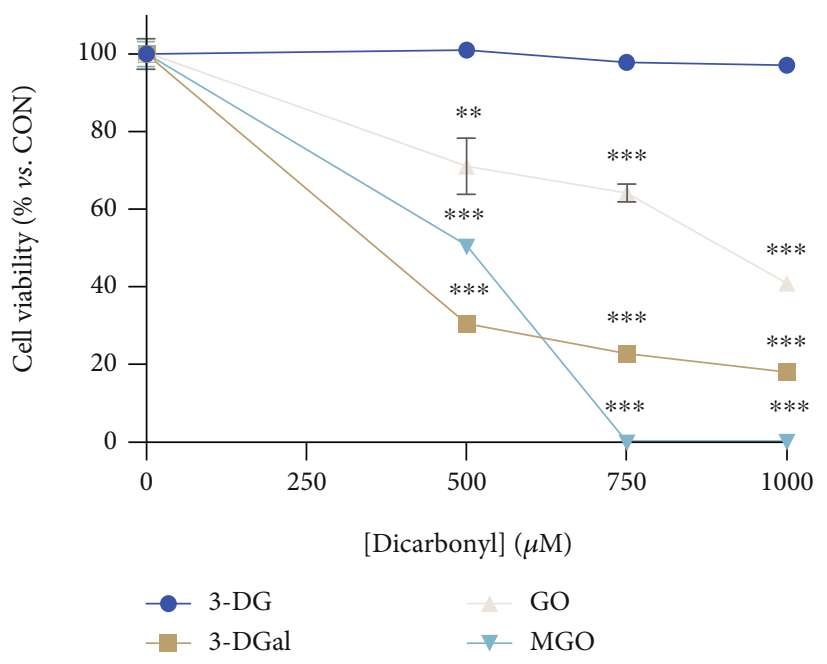

(a)

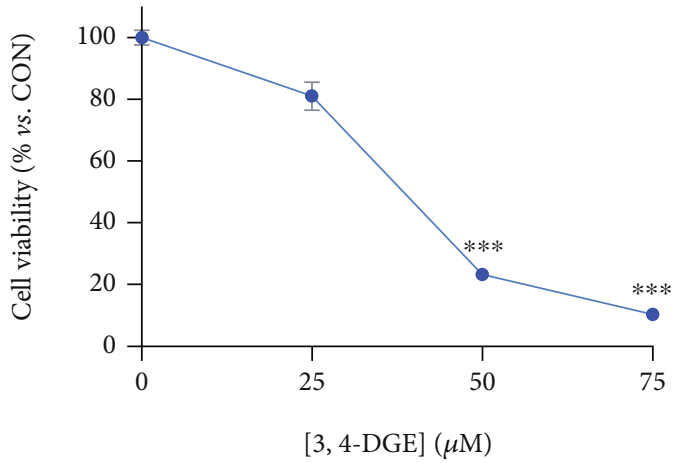

(b)

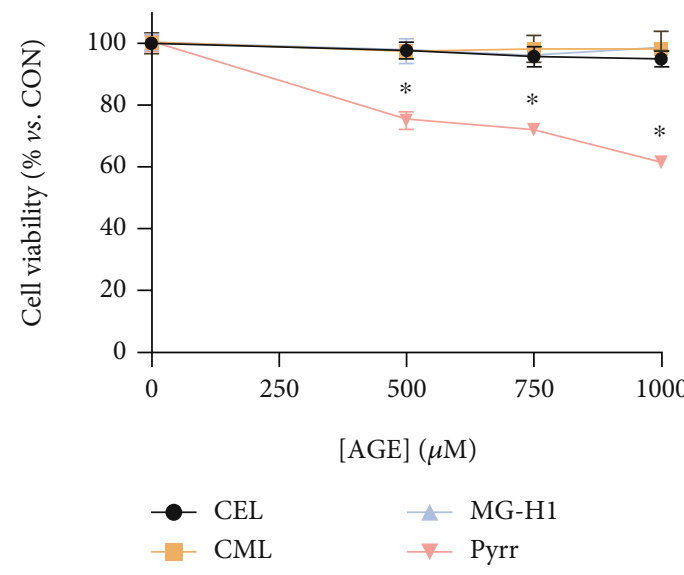

(c)

Figure 2: Effect of individual 1,2-dicarbonyls and glycated amino acids on cell viability. (a) Cell viability upon incubation with individual 1,2-dicarbonyls. (b) Cell viability upon incubation with 3,4-DGE. (c) Cell viability upon incubation with individual glycated amino acids. Results are expressed as mean $\pm \operatorname{SEM}(n=6) .{ }^{*} p<0.05 v s . \mathrm{CON},{ }^{* *} p<0.01 v s$. CON, ${ }^{* * *} p<0.001 v s$. CON.

3-DGal, GO and MGO significantly cytotoxic compared to the control group above a concentration of $500 \mu \mathrm{mol} / \mathrm{L}$. When cells were incubated with 3 -DGal, the viability of the cells was significantly reduced by $82 \%$ at $750 \mu \mathrm{mol} / \mathrm{L}$. In the case of GO, cell viability was decreased by $59 \%$ when tested at a concentration of $1 \mathrm{mmol} / \mathrm{L}$. No surviving cells were found when cultured with $750 \mu \mathrm{mol} / \mathrm{L} \mathrm{MGO}$, and a cytotoxicity of almost $50 \%$ with a concentration of $500 \mu \mathrm{mol} / \mathrm{L}$ was observed. The chemically the most reactive dicarbonyl 3,4DGE was found to be also the most cytotoxic compound. Concentrations of the compound above $50 \mu \mathrm{mol} / \mathrm{L}$ were already significantly cytotoxic, and cell viability after the treatment of the cells with $75 \mu \mathrm{mol} / \mathrm{L} 3,4-\mathrm{DGE}$ was dramatically reduced until viability of $11 \%$ (Figure 2(b)).

On the other hand, glycated amino acids were much less cytotoxic than 1,2-dicarbonyls, since only Pyrr, at a concentration higher than $500 \mu \mathrm{mol} / \mathrm{L}$, was able to reduce the viability of $\mathrm{HaCaT}$ cells in culture. Thus, $1 \mathrm{mmol} / \mathrm{L}$ Pyrr decreased MTT reduction to $61.58 \%$. Although, the cells did not show any signs of cell damage when observed under the microscope. This indicates that Pyrr could affect both proliferation and mitochondrial activity instead of increasing cytotoxicity of HaCaT cells since MTT assay cannot discriminate between them. Interestingly, incubation with CEL, CML, MG-H1, and 3-DG did not show any sign of cell damage (Figure 2(c)). Thus, the following assays addressing individual mechanisms of cytotoxicity were performed only with the dicarbonyl compounds.

3.2. GO and MGO Retarded the Cell Cycle in HaCaT Cells. The progression of cell cycle upon incubation with these compounds was assayed to study whether these compounds might reduce cell proliferation and then alter the cell cycle. Thus, cells were incubated with 3-DGal, 3,4-DGE, GO, and MGO for 48 hours, and after that, the cell cycle was studied, staining the cells with PI and, then, analyzing them by flow cytometry. It was found that 3-DGal did not show any change in cell cycle progression compared to control cells. However, 3,4-DGE significantly decreased the number of cells in $G_{0} / G_{1}$ phase when compared to the control group. On the other hand, GO and MGO significantly increased the number of cells retained in the $S$ phase, indicating an 
arrest in the S phase due to activation of the S-phase DNA damage checkpoint (Figure 3).

\subsection{Antioxidant NAC Recovered 1,2-Dicarbonyl-Mediated} Cell Death. It has been proposed that AGEs and their precursors might increase oxidative stress, but this fact was not previously demonstrated with isolated 1,2-dicarbonyl compounds. Consequently, to elucidate whether they were increasing ROS production in this cell culture model and whether cytotoxicity might depend on free radicals, the effect of the antioxidant NAC in preventing cell death induced by these compounds was studied. Thus, cells were preincubated for 30 minutes with $10 \mathrm{mmol} / \mathrm{L} \mathrm{NAC}$, and then, the 1,2-dicarbonyls 3-DGal, 3,4-DGE, GO, and MGO were added to the cell culture without removing NAC. After 48 hours of incubation, cell viability was assayed by trypan blue exclusion.

It was found that preincubation with NAC prevented the cytotoxicity of 1,2-dicarbonyls. Upon incubation with 3DGal and 3,4-DGE, cells showed blebs and irregular borders, an indication for cell damage, which was highly prevented upon coincubation with NAC. Importantly, in the case of MGO incubation, a lot of the cells showed blebs, and cell integrity was completely lost in most cases. Although, when coincubating the cells with NAC, the cell morphology was equal to that observed in the control cells (Figure 4(a)). The role of NAC to prevent the cytotoxicity of 1,2-dicarbonyls was studied by trypan blue exclusion since NAC interferes with formazan, and it cannot be employed in MTT assay. Thus, we found that NAC prevented the cytotoxicity of $1 \mathrm{mmol} / \mathrm{L}$ 3-DGal (Figure 4(b)). Similarly, NAC completely prevented the cytotoxicity and recovered cell viability from $84 \%$ to $96.97 \%$ when cells were treated with $100 \mu \mathrm{mol} / \mathrm{L}$ 3,4-DGE (Figure 4(c)). Interestingly, a reduction of cell viability by GO was not found when trypan blue exclusion was employed, suggesting an effect of the compound on the mitochondrial metabolism of the cells (Figure 4(d)). Finally, the most remarkable result was obtained within the MGO group. Thus, $750 \mu \mathrm{mol} / \mathrm{L}$ MGO treatment reduced the viability of $\mathrm{HaCaT}$ cells to an $18.33 \%$. NAC preincubation recovered the viability almost completely to $94 \%$ (Figure 4(e)). Altogether, these data account for a feasible role of ROS in mediating 1,2-dicarbonyls cytotoxicity.

3.4. 1,2-Dicarbonyls Caused an Increase in ROS and the Production of Antioxidant Enzymes. Then, it was further studied whether 1,2-dicarbonyls triggered ROS production in the human keratinocytes $\mathrm{HaCaT}$ cells. Therefore, cells were treated with 3-DGal, 3,4-DGE, GO, and MGO for 48 hours and stained with DHR-123, DHE, and MitoSOX ${ }^{\mathrm{TM}}$ Red, and finally analyzed by flow cytometry. Interestingly, individual 1,2-dicarbonyls increased the production of the species measured in $\mathrm{HaCaT}$ cells, among the different 1,2-dicarbonyls, GO, and MGO caused a higher ROS production than 3-DGal and 3,4DGE. Furthermore, superoxide was increased more than twice by MGO than the control group (Figures $5(a)-5(c)$ ).

Because of increasing free radicals' production, cells naturally increase the production of antioxidant enzymes. To evaluate the effect of 1,2-dicarbonyls on the production of antioxidant enzymes as a consequence of the increment of the free radicals produced, cells were incubated with the 1,2-dicarbonyls 3-DGal, GO, and MGO for 48 hours, and the levels of SOD1, SOD2, and catalase were studied by western-blot. In the case of SOD1, only GO significantly increased its levels. However, 3-DGal and GO increased SOD2. The production of CAT did not change after treatment. Besides, since the production of peroxides was increased in the cells upon incubation with 1,2-dicarbonyls, the ratio between catalase and SOD2 production was also studied. Although there was a relative increase in the SOD2/CAT ratio when cells were incubated with 1,2-dicarbonyls, especially GO and MGO, the differences were not statistically significant between groups (Figures $5(\mathrm{~d})-5(\mathrm{~h})$ ).

3.5. MGO Induced Cell Death by Apoptosis in HaCaT Cells. It remains to be determined how 1,2-dicarbonyls lead to cell death and if individual 1,2-dicarbonyls cause cell death by the same mechanism. Therefore, it was firstly assayed whether cells might be dying by apoptosis. To investigate that, cells were incubated with the 1,2-dicarbonyls 3-DG, 3DGal, 3,4-DGE, GO, and MGO for 48 hours, and after that, they were stained with Annexin- $\mathrm{V}$ and 7-AAD and analyzed by flow cytometry.

It was found that the number of apoptotic cells did not change between the control group and cells incubated with 3-DG, 3-DGal, 3,4-DGE, and GO. Outstandingly, the number of cells dying by apoptosis upon MGO incubation was greatly increased, and it reached a mean of $85.35 \%$ of the total cells (Figures 6(a) and 6(b)).

To confirm that cells were dying by caspase-mediated apoptosis when incubated with MGO, cells were preincubated with the inhibitor of caspase Q-VD-OPh for 30 minutes, and after that, MGO was added to the cell culture. Cells were incubated with both compounds for 48 hours, and then, cell viability was assayed by trypan blue exclusion. When incubating the cells with MGO, they showed blebs and cell integrity was completely lost in most cases. Although, when coincubating the cells with this 1,2-dicarbonyl and the inhibitor of caspases, cell morphology was greatly recovered, the number of cells displaying the morphology observed in the control cells was increased (Figure 6(d)). It was found that cell viability was significantly recovered upon preincubation with q-VD-OPH and it consequently pointed to apoptosis as the most feasible cell death mechanism produced by MGO (Figure 6(c)).

After that, we used a series of other cell death inhibitors to decipher the cell death mechanism by which cells were dying when incubated with 3-DGal and 3,4-DGE. Hence, we preincubated cells with Ferrostatin-1, an inhibitor of ferroptosis; with 3-MA, an inhibitor of autophagy; and Necrostatin-1, an inhibitor of necroptosis, for 30 minutes, and after that, 3-DGal and 3,4-DGE were added to the cell culture. Cells were incubated with both compounds for 48 hours, and then, cell viability was assayed by trypan blue exclusion. When cells were incubated with 3-DGal and 3,4DGE, some cells showed irregular borders and blebs. Nevertheless, when cells were coincubated with 1,2-dicarbonyls and cell death inhibitors, no recovery of the cell morphology was noticed (Figure 7(a)). Similarly, when cells were 

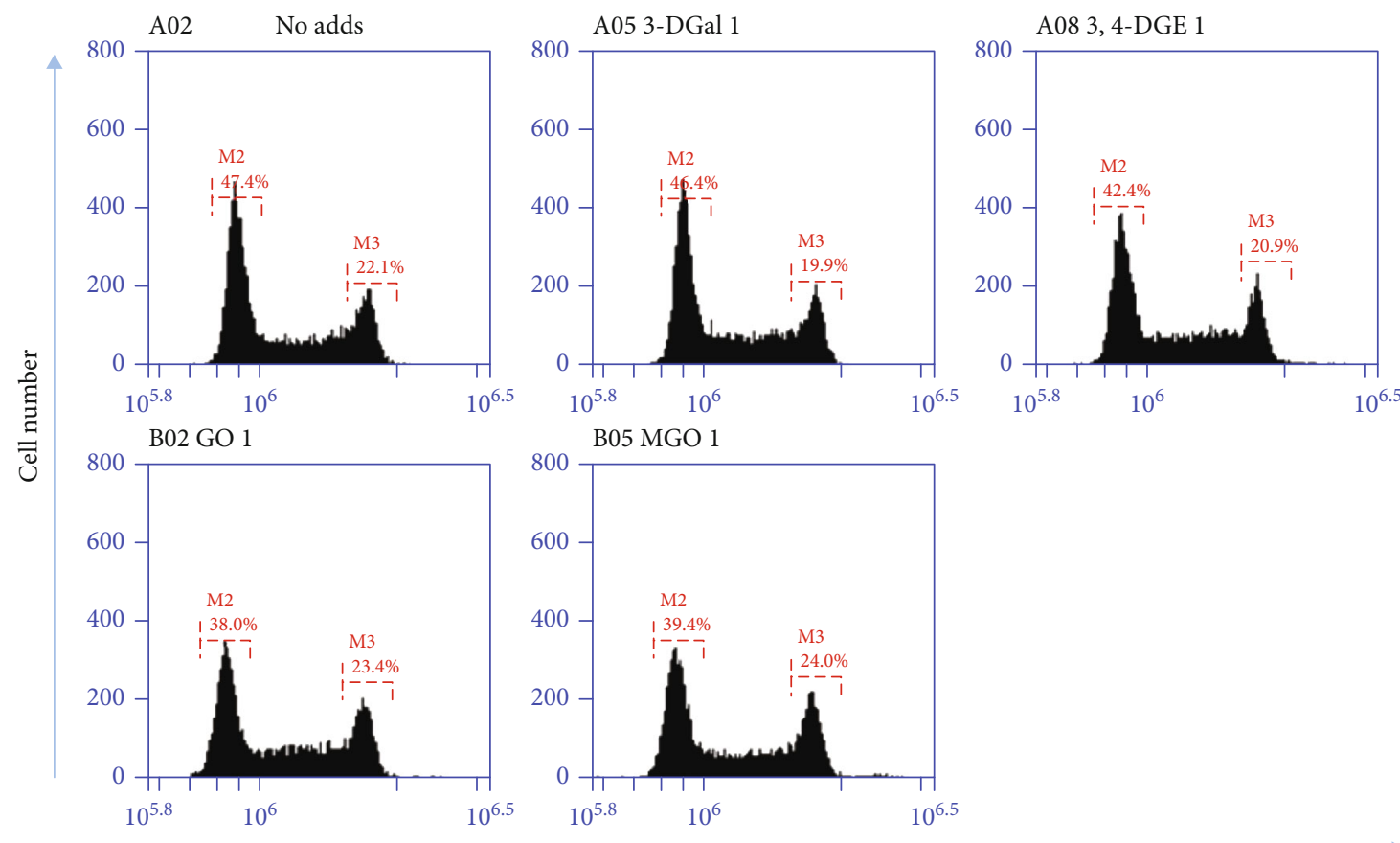

Propidium iodide

(a)

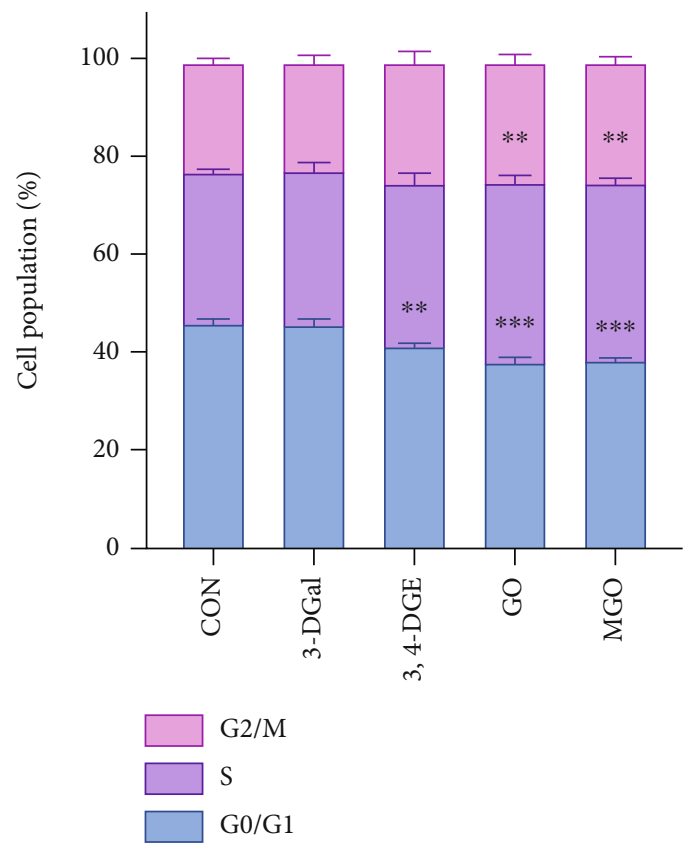

(b)

Figure 3: Effect of individual 1,2-dicarbonyls on cell cycle. (a) Propidium iodide fluorescence was measured by flow cytometry. One representative experiment is shown. (b) Cell population percentage in each stage of cell cycle. Here, cell treatments consisted of $750 \mu \mathrm{M}$ 3-DGal, $75 \mu \mathrm{M}$ 3,4-DGE, $1 \mathrm{mM} \mathrm{GO}$, and $500 \mu \mathrm{M}$ MGO. Results are expressed as mean $\pm \mathrm{SEM}(n=3) .{ }^{* *} p<0.01 v s$. CON, ${ }^{* * *} p<0.001$ vs. CON.

incubated with the 1,2-dicarbonyls and inhibitors of ferroptosis, autophagy, and necroptosis, cell viability was not recovered in any of the assayed conditions (Figure $7(b)$ ).

3.6. 3-DGal and 3,4-DGE Activated the Inflammatory Pathways of NF- $\kappa B$ and NLRP3 Inflammasome. Given the impact on cell viability derived from the exposure of the 1,2-dicarbonyl compounds 3,4-DGE, 3-DGal, and 3-DG, and the AGE Pyrr, the subsequent analyses were structured to understand which pathways were underlying the cytotoxicity involved in this reduction of cell viability. The phosphorylation of the $\mathrm{IKK} \alpha / \beta$ and $\mathrm{I} \kappa \mathrm{B} \alpha$ proteins was 


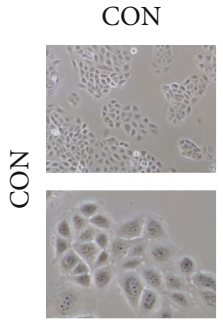

3-DGal
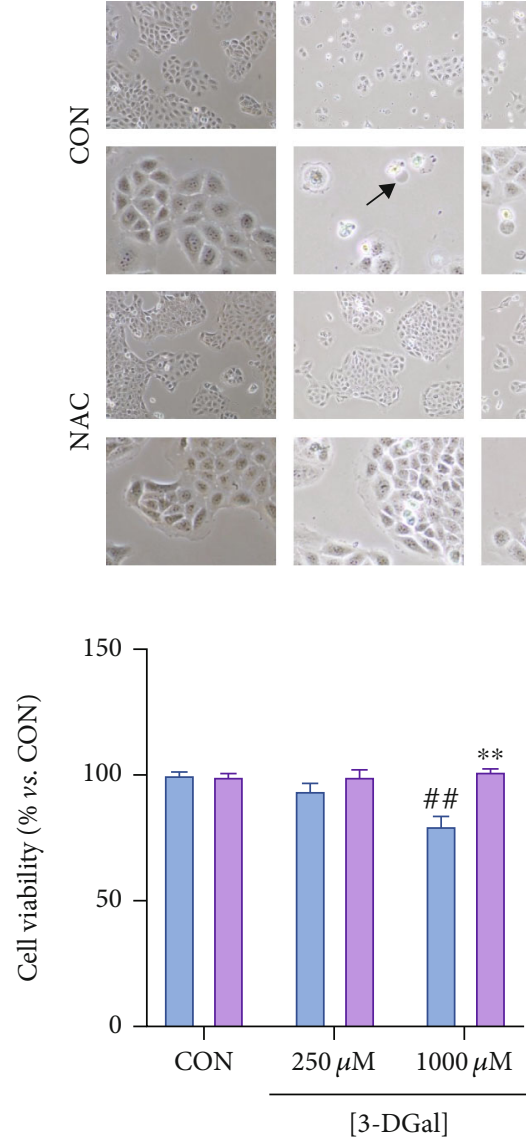

$\square$ CON
$\square$ NAC

(b)

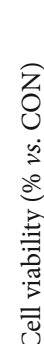

3
0
0
0
0
0
0
0
0
0
0
0
0
0

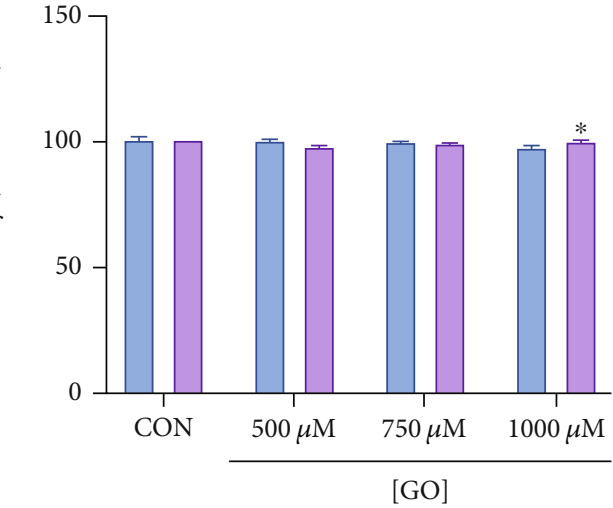

$\square \mathrm{CON}$

NAC
3, 4-DGE
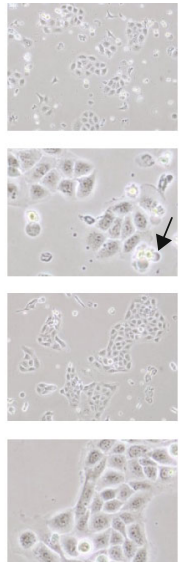

(a)

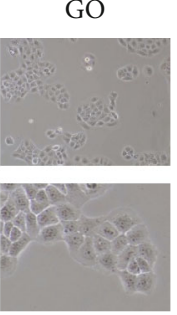

MGO
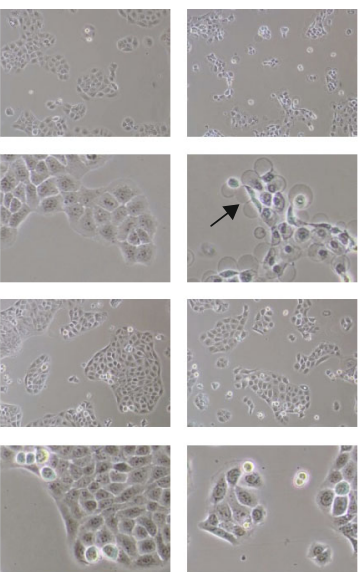

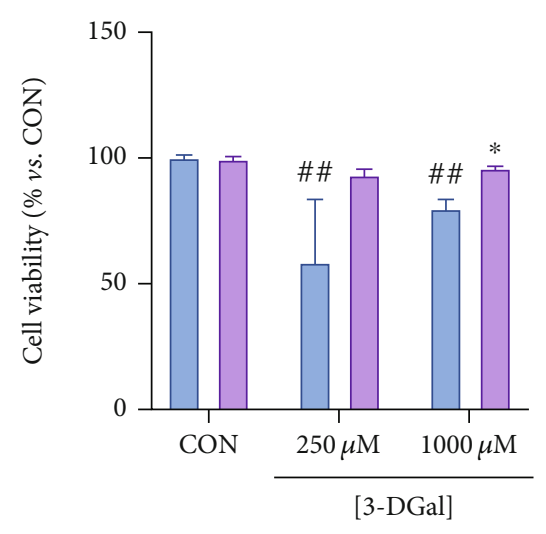

$\square \mathrm{CON}$

NAC

(c)

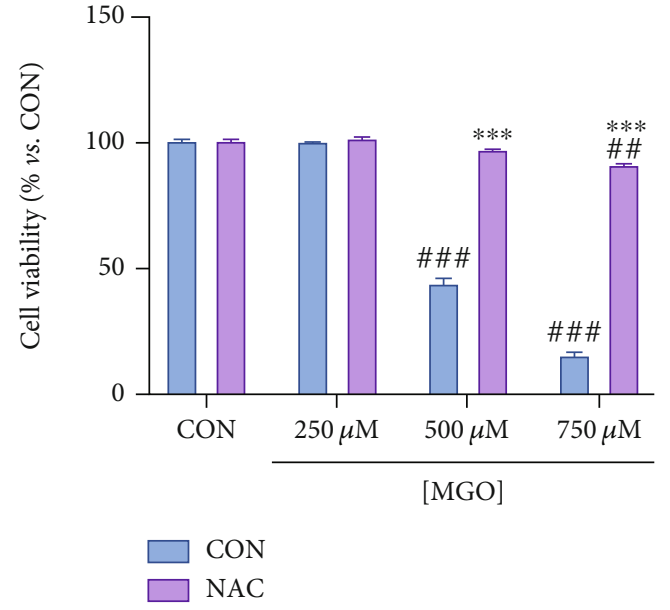

(e)

FIGURE 4: Cell viability recovery after coincubation with 1,2-dicarbonyls and NAC. (a) A representative micrograph for each condition is shown. For each condition, micrographs shown in the first row were taken at 100x original magnification, and micrographs in the second row were taken at 400x original magnification. Arrows indicate blebs. (b) Cell viability upon coincubation with 3-DGal and NAC. (c) Cell viability upon coincubation with 3,4-DGE and NAC. (d) Cell viability upon coincubation with GO and NAC. (e) Cell viability upon coincubation with MGO and NAC. Results are expressed as mean $\pm \operatorname{SEM}(n=3) .{ }^{*} p<0.05 v s$. CON, ${ }^{* *} p<0.01 v s$. CON, ${ }^{* * *} p<0.001 v s$. CON, ${ }^{\# \#} p<0.01$ vs. no 1,2-dicarbonyl, ${ }^{\# \# \# ~}<0.001$ vs. no 1,2-dicarbonyl. 


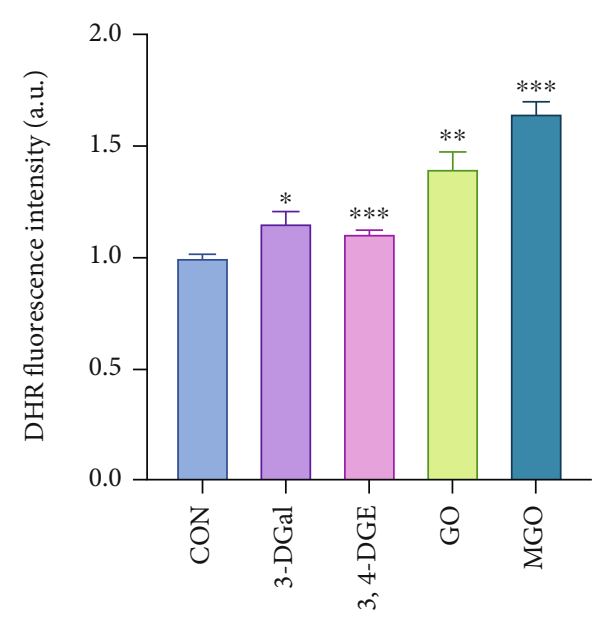

(a)

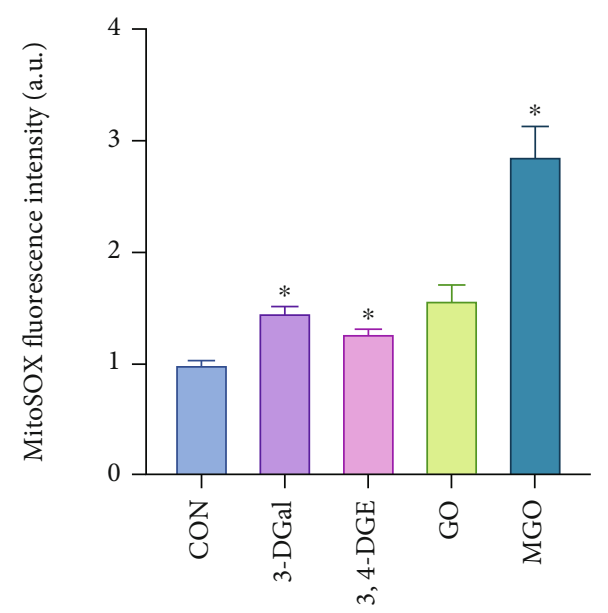

(c)

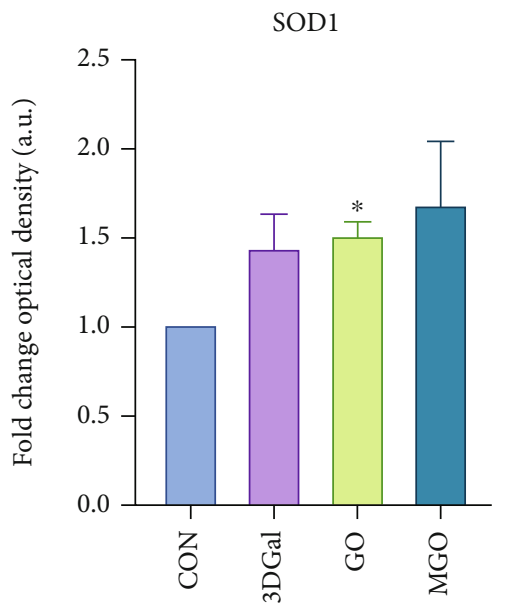

(e)

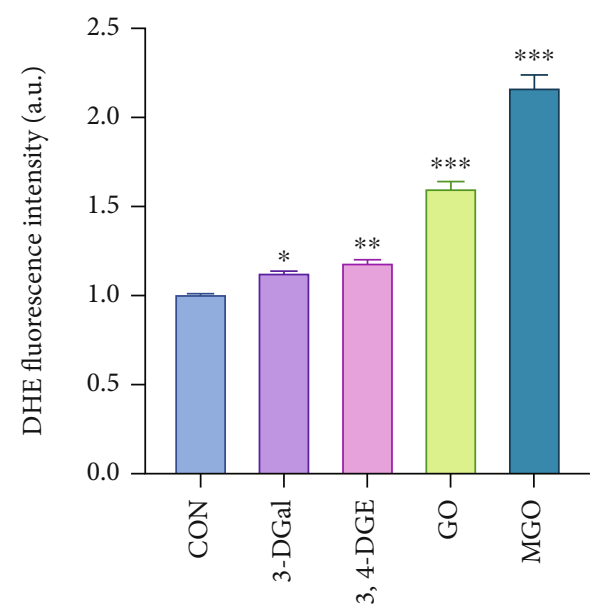

(b)

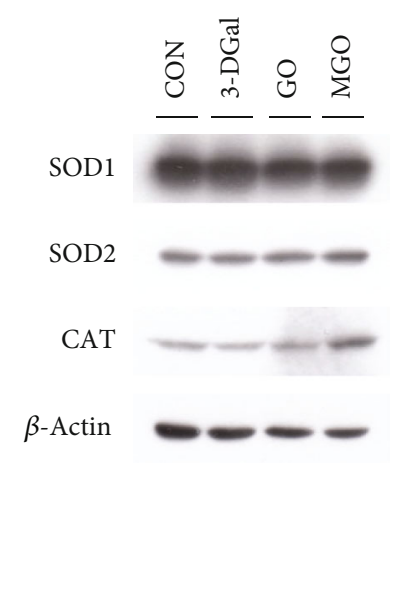

(d)

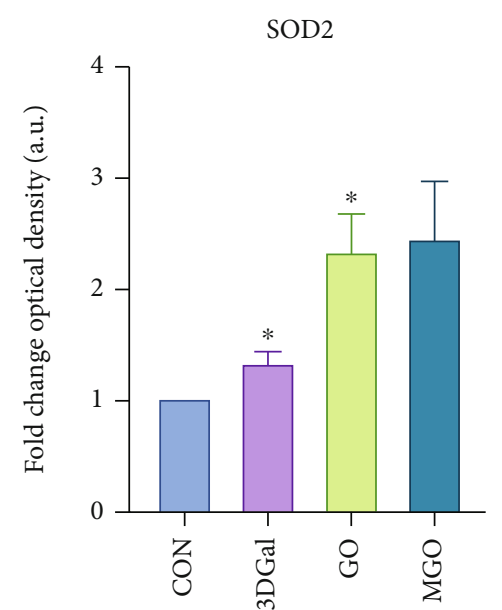

(f)

Figure 5: Continued. 
CAT

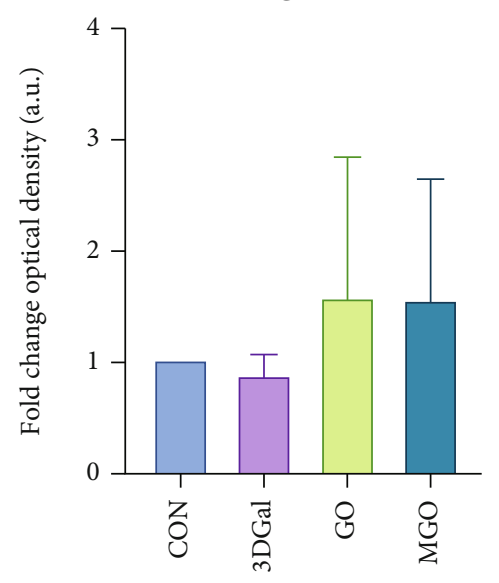

(g)

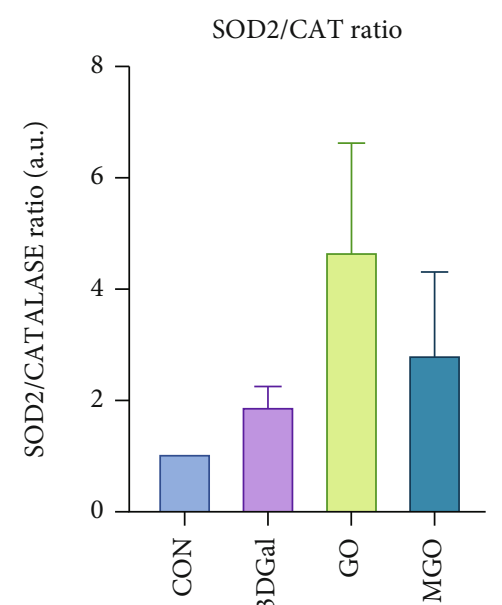

(h)

Figure 5: Free radical and antioxidant enzymes production upon application of 1,2-dicarbonyls. (a) Production of peroxide and peroxynitrite as measured by DHR fluorescence intensity. (b) Production of superoxide as measured by DHE fluorescence intensity. (c) Production of mitochondrial superoxide as measures by MitoSOX fluorescence intensity. (d) Representative western blot experiment. (e) Production of SOD1 as analyzed by quantification of western blot optical density. (f) Production of SOD2 as analyzed by quantification of western blot optical density. (g) Production of catalase as analyzed by quantification of western blot optical density. (h) Ratio between the production of SOD2 and catalase. Arbitrary 1.0 value was given to the WT group. Here, cell treatments consisted of 750 $\mu \mathrm{M} 3-\mathrm{DGal}, 75 \mu \mathrm{M} 3,4-\mathrm{DGE}$, $1 \mathrm{mM}$ GO, and $500 \mu \mathrm{M}$ MGO. Results are expressed as mean $\pm \operatorname{SEM}(n=3) .{ }^{*} p<0.05 v s$. CON, ${ }^{* *} p<0.01 v s . \mathrm{CON},{ }^{* * *} p<0.001 v s . \mathrm{CON}$.

evaluated, respectively, on the amino acid residues Ser176/180 and Ser32/36. IKK phosphorylation values are shown as the ratio between the phosphorylated protein and the total protein in the whole protein extract of the samples examined. IKK phosphorylation levels were significantly increased in the 3,4-DGE and 3-DGal treatment groups compared to the control group. Furthermore, these values are comparable to each other. On the other hand, there is no evidence of IKK phosphorylation significantly different from the control group for the samples treated with 3-DG. The consequent phosphorylation of the $\mathrm{I} \kappa \mathrm{B} \alpha$ protein was then evaluated. It can be seen that the observed trend for IKK phosphorylation was comparable to that of $\mathrm{I} \kappa \mathrm{B} \alpha$ phosphorylation. In particular, as regards the parameters related to the phosphorylation both of IKK and of $\mathrm{I} \kappa \mathrm{B} \alpha$, the phosphorylation appears to be tripled for 3-DGal and slightly more than tripled for 3,4-DGE compared to the control. By analyzing the data related to the 3-DG and Pyrr groups, these are comparable to the control for both parameters. To evaluate the translocation of NF- $\kappa \mathrm{B}$ at the nuclear level, the presence of this factor in the cytosolic protein extract and the nuclear protein extract was tested. The results are expressed as the ratio between cytosolic NF- $\kappa$ B and nuclear NF- $\kappa$ B. The results show a significant nuclear translocation of NF- $\kappa$ B in $\mathrm{HaCaT}$ cells treated with 3,4-DGE. Nuclear NF- $\kappa \mathrm{B}$ is more than five times higher compared to the control. Furthermore, regarding the 3-DGal group, the translocation of NF- $\kappa \mathrm{B}$ at the nuclear level can be highlighted. Despite the high standard deviation, it can be seen that the presence of the transcription factor in the nucleus is approximately four times the same in the control group (Figure 8).

Similar results were obtained when the effects on the modulation of the NLRP3 inflammasome pathway were evaluated. As shown in Figure 9, the expression of NLRP3 is more than doubled in the 3,4-DGE and 3-DGal treatment groups compared to the control group. Exactly as observed for the other markers previously examined, the two groups are comparable to each other. However, it should be considered that the exposure concentration of keratinocytes to 3,4DGE was 10 times lower than that of the exposure to 3-DGal. Following the evaluation of the expression of NLRP3 in the groups under analysis, it was decided to evaluate its activation by searching for the cleaved form of gasdermin-D (GSDMD). NLRP3, once activated, can activate caspase-1 that can cleave (in addition to, for example, the most studied interleukin-1 $\beta$ ) the GSDMD. The $N$-terminal residue of GSDMD (at $30 \mathrm{kDa}$ ) is then able to form transmembrane pores. Figure 10 also shows the analysis of the inactive form of GSDMD (Pro-GSDMD) and the active form (Activated GSDMD) production in keratinocytes treated with 3-DGal, 3,4-DGE, Pyrr, and 3-DG. The groups exposed to 3,4-DGE and 3-DGal, in addition to causing an increase in the expression of NLRP3 (as seen above), also showed the activation of GSDMD; in these groups of treatment, GSDMD was about five times higher than the inactive form. In contrast, the 3-DG and Pyrr groups did not show any difference in the presence of the two forms compared to the control group.

\section{Discussion}

In the present manuscript, we report for the first time the biological effects that individual glycated amino acids and 1,2-dicarbonyls induce in a keratinocyte cell model. We found that most of the assayed 1,2-dicarbonyls are cytotoxic at a concentration ranging from $50 \mu \mathrm{mol} / \mathrm{L}$ to $500 \mu \mathrm{mol} / \mathrm{L}$, whereas glycated amino acids do not alter cell viability. Hence, 3-DGal, 3,4-DGE, GO, and MGO highly reduce cell viability. When coincubating the cells with NAC, we found 

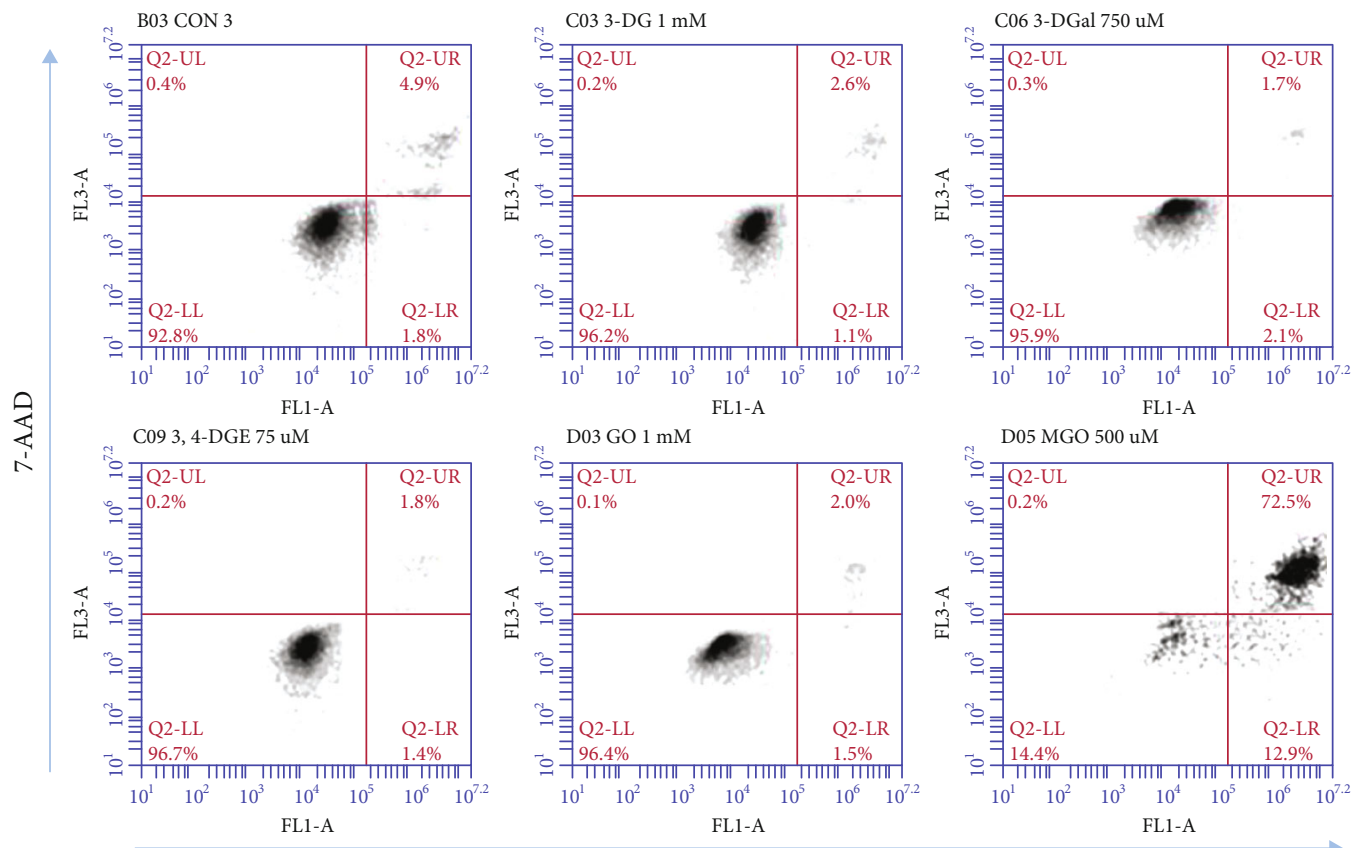

Annexin V-FITC

(a)
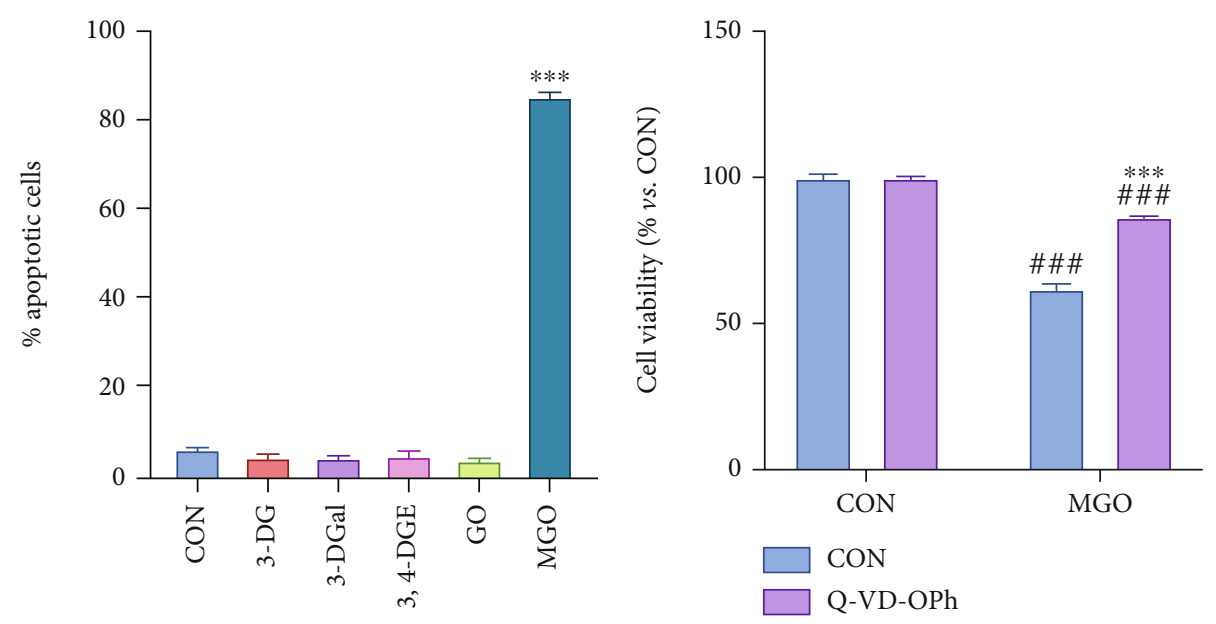

(b)

(c)

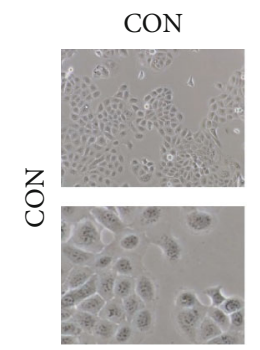

MGO
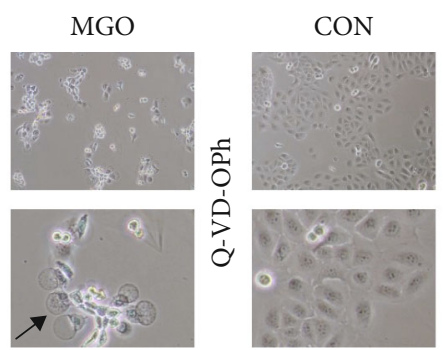

MGO

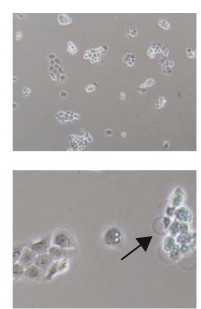

(d)

FIgURE 6: Cell death by apoptosis after incubation with 1,2-dicarbonyls. (a) Annexin-V and 7-AAD fluorescence was measured by flow cytometry. One representative experiment is shown. (b) Percentage of apoptotic cells in the cell culture. Positive cells for Annexin V and for both Annexin V and 7-AAD were considered apoptotic. (c) Cell viability upon coincubation with MGO and the apoptosis inhibitor Q-VD-OPh. (d) Cell viability recovers after coincubation with apoptosis inhibitor Q-VD-OPh. A representative micrograph for each condition is shown. For each condition, micrographs shown in the first row were taken at 100x original magnification, and micrographs in the second row were taken at 400x original magnification. Arrows indicate blebs. Here, cell treatments consisted of $1 \mathrm{mM}$ 3-DG, $750 \mu \mathrm{M}$ 3-DGal, $75 \mu \mathrm{M}$ 3,4-DGE, $1 \mathrm{mM} \mathrm{GO}$, and $500 \mu \mathrm{M}$ MGO. Results are expressed as mean $\pm \mathrm{SEM}(n=3)$. ${ }^{* * *} p<0.001 v$.

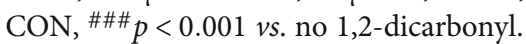



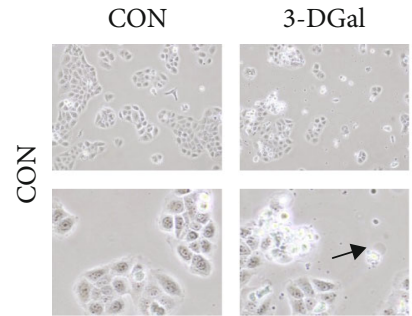

3, 4-DGE
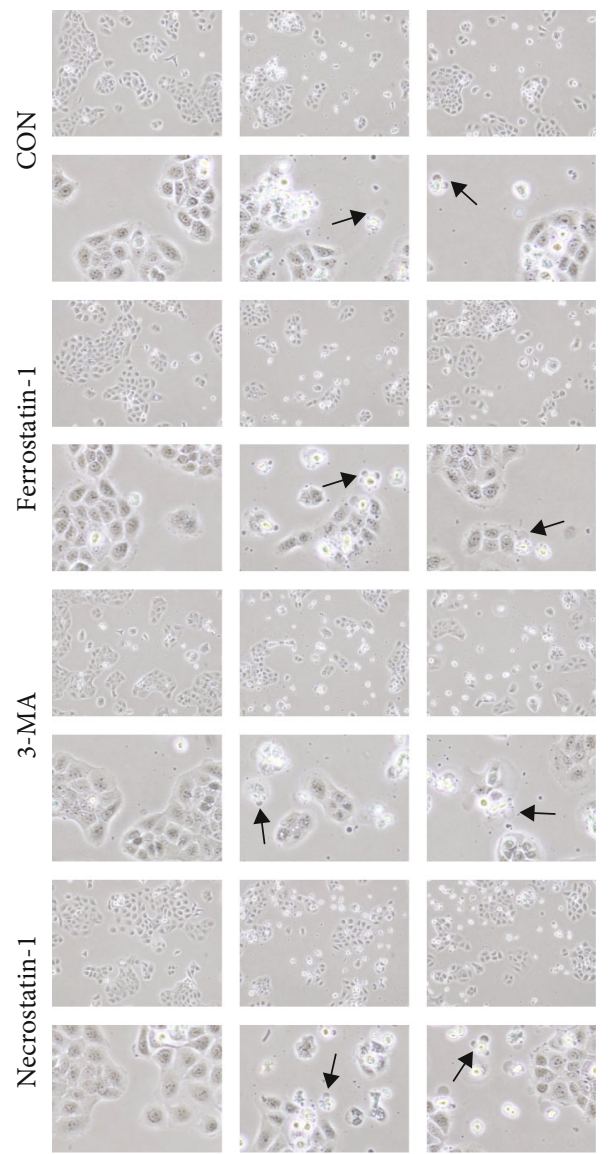

(a)

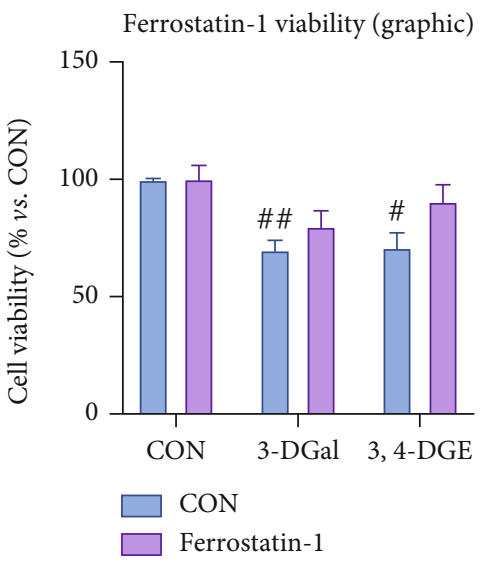

(b)

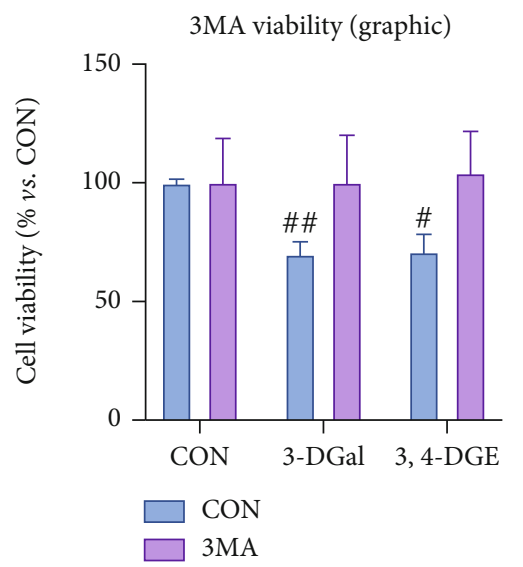

(c)

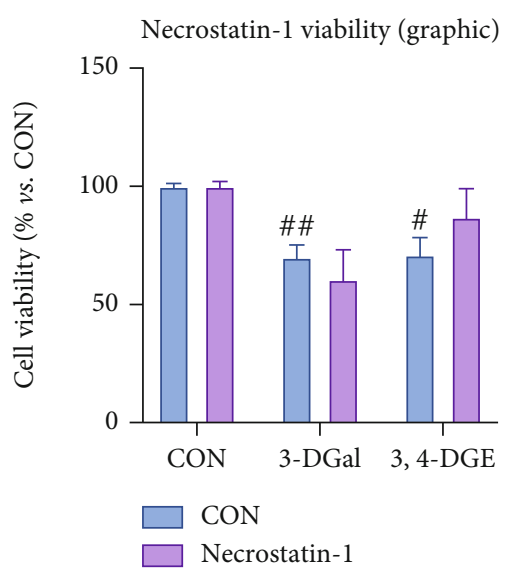

(d)

FIGURE 7: Cell viability recovery after coincubation with cell death inhibitors. (a) A representative micrograph for each condition is shown. For each condition, micrographs shown in the first row were taken at 100x original magnification, and micrographs in the second row were taken at 400x original magnification. Arrows indicate blebs. (b) Cell viability upon coincubation with the ferroptosis inhibitor Ferrostatin-1. (c) Cell viability upon coincubation with the autophagy inhibitor 3-MA. (d) Cell viability upon coincubation with the necroptosis inhibitor Necrostatin-1. Here, cell treatments consisted of $750 \mu \mathrm{M} 3$-DGal and $75 \mu \mathrm{M} 3,4$-DGE. Results are expressed as mean \pm SEM $(n=3)$. ${ }^{\#} p<0.05$ vs. no 1,2-dicarbonyl, ${ }^{\# \#} p<0.01$ vs. no 1,2-dicarbonyl.

that this antioxidant prevents the decrease in cell viability caused by 1,2-dicarbonyls, which accounts for a possible role of ROS in mediating 1,2-dicarbonyls cytotoxicity. Indeed, we found that 1,2-dicarbonyls increase peroxide, peroxynitrite, and superoxide production in cells, and therefore, the production of SOD1 and SOD2 counters an excessive ROS production. Finally, we found that the 1,2-dicarbonyl MGO leads to cell death by caspase-mediated apoptosis and that 

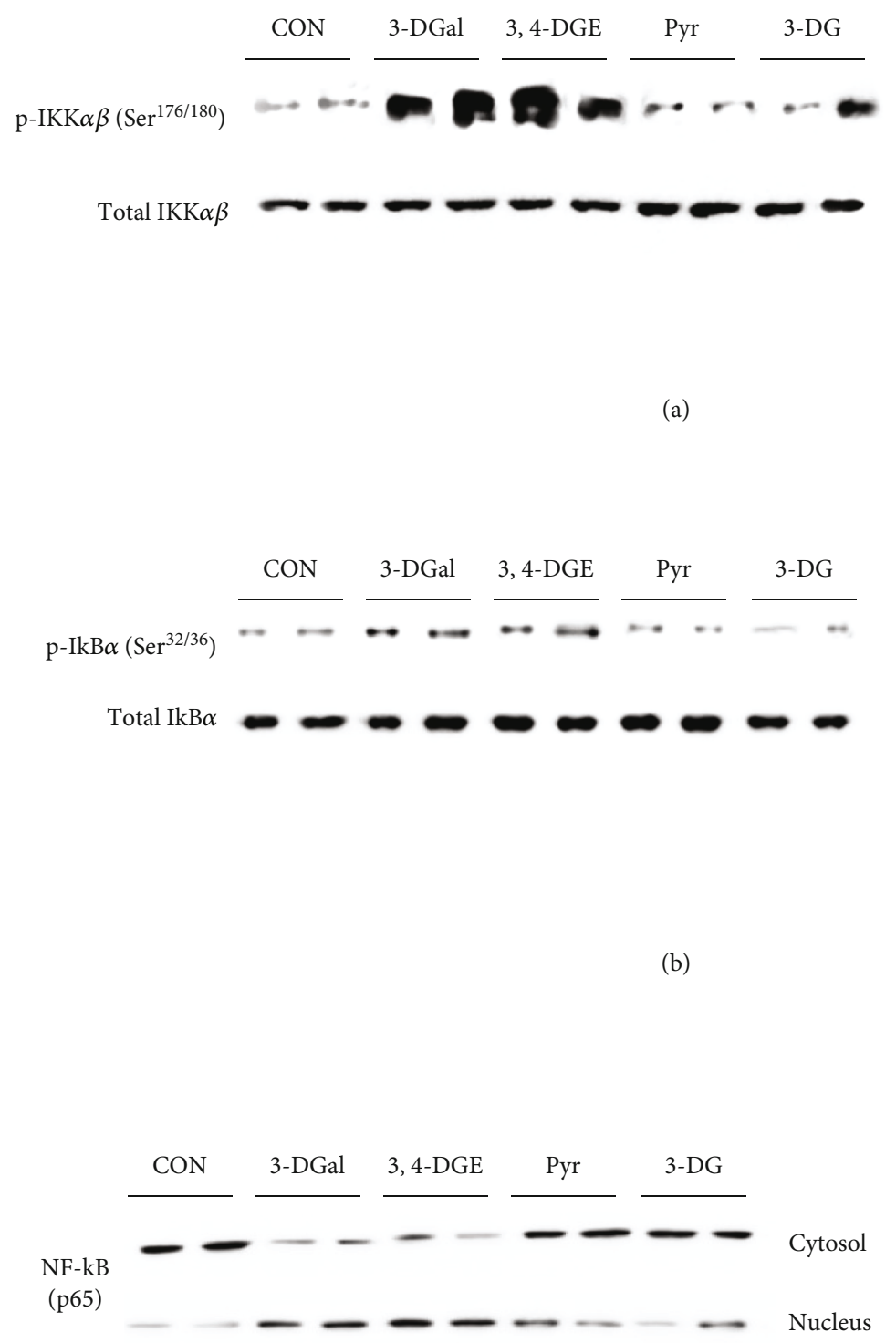

(c) (a)

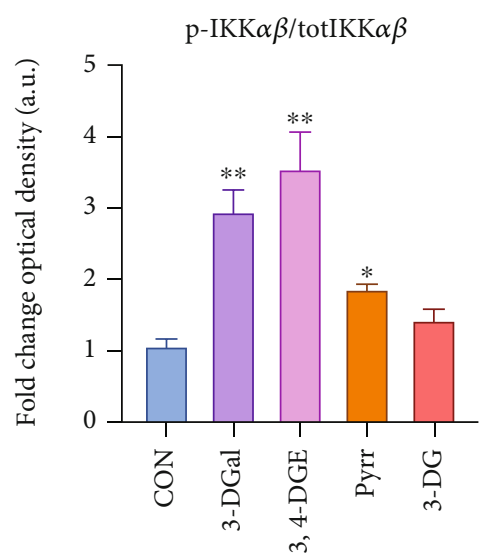

$\mathrm{p}-\mathrm{IkB} \alpha / \operatorname{totIkB} \alpha$

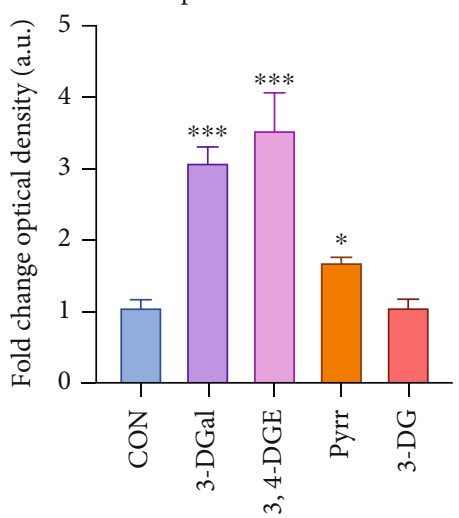

(b)

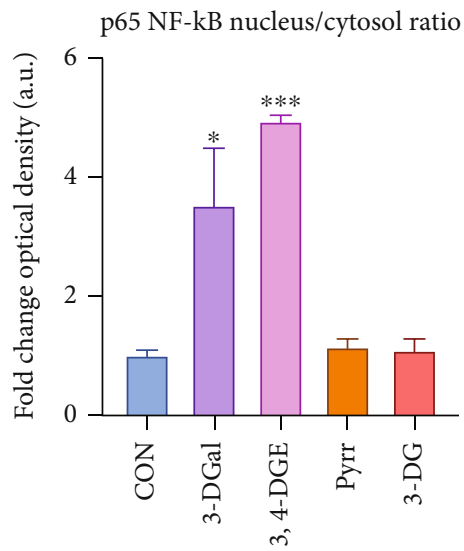

FIGURE 8: Activation of the NF- $\kappa$ B pathway upon incubation with 1,2-dicarbonyls. (a) IKK $\alpha \beta$ phosphorylation. A representative western-blot experiment is shown. Graphic represents the ratio between the production of p-IKK $\alpha \beta$ and total IKK $\alpha \beta$ as analyzed by quantification of western blot optical density. (b) I $\kappa \mathrm{B}$ phosphorylation. A representative western blot experiment is shown. Graphic represents the ratio between the production of $\mathrm{I} \kappa \mathrm{B}$ and total $\mathrm{I} \kappa \mathrm{B}$ as analyzed by quantification of western blot optical density. (c) NF- $\kappa \mathrm{B}$ activation. A representative western blot experiment is shown. Graphic represents the ratio between the production of nuclear p65 NF- $\kappa \mathrm{B}$ and cytosolic $\mathrm{NF}-\kappa \mathrm{B}$ as analyzed by quantification of western blot optical density. Arbitrary 1.0 value was given to the CON group. Here, cell treatments consisted of $750 \mu \mathrm{M} 3$-DGal, $75 \mu \mathrm{M}$ 3,4-DGE, $1 \mathrm{mM}$ Pyrr, and $1 \mathrm{mM} 3$-DG. Results are expressed as mean \pm SEM $(n=3)$. ${ }^{*} p<0.05 v$. $\mathrm{CON},{ }^{* *} p<0.01$ vs. CON, ${ }^{* * *} p<0.001$ vs. CON.

3-DGal and 3,4-DGE activate the NF- $\kappa \mathrm{B}$ pathway and drive the activation of NLRP-3 inflammasome, which triggers cell death by pyroptosis.
Up to now, most of the studies that have been published in the field of the biological and pathological roles of AGEs have been conducted using glycated albumin or a mixture 

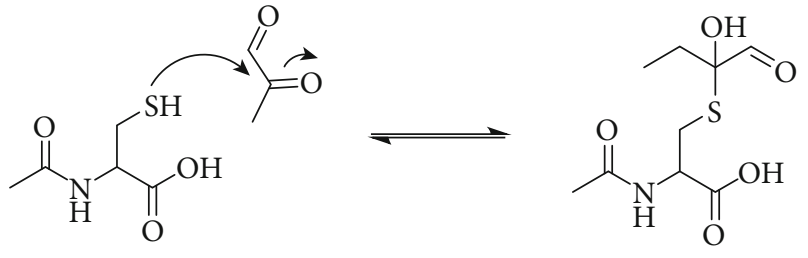

FIgURE 9: Reaction of $\mathrm{N}$-acetylcysteine with MGO under formation of a hemithioacetal.

of different AGEs to perform the experiments. The procedures used to obtain these substances widely vary from laboratory to laboratory, usually following nonreproducible methodologies, making the results obtained between different research groups hardly comparable. Moreover, AGEs comprise an extensive variety of compounds, with each compound being structurally very different from the other, and thus, they might not exert the same effects in cellular and animal models. In addition to AGEs, albumin glycation produces 1,2 dicarbonyls. Therefore, there is a lack of reproducible methodology, and it is necessary that the role of individual AGEs and 1,2-dicarbonyls should be investigated.

To perform our experiments, the most prevalent glycated amino acids and 1,2-dicarbonyls in foods were synthesized to assay the effects that they might produce individually in cell culture. Since diet is a source of exogenous products of glycation, and the mouth is the first tissue in contact with these compounds, we used an oral mucosa in vitro cell model, using the human keratinocyte cell line $\mathrm{HaCaT}$. We found different cytotoxic effects depending on the compound tested. On the one hand, some of the best characterized glycated amino acids, such as CEL and CML, were not cytotoxic in our cell model. As it has been reported, these compounds are present in the plasma of diabetic patients in a concentration up to $1.2 \mu \mathrm{mol} / \mathrm{L}$ for CEL and $2.9 \mu \mathrm{mol} / \mathrm{L}$ for CML and at a concentration up to $1.7 \mu \mathrm{mol} / \mathrm{L}$ and $4.9 \mu \mathrm{mol} / \mathrm{L}$, respectively, in the plasma in type I diabetes and impaired renal function patients [47]. It has been also reported that plasma CEL/CML concentrations in chronic kidney disease patients are $336 \mathrm{nmol} / \mathrm{L}$ and $111 \mathrm{nmol} / \mathrm{L}$, respectively [48]. Moreover, in one study using endothelial progenitor cells, CEL and CML up to a concentration of $4.58 \mu \mathrm{mol} / \mathrm{L}$ and $4.90 \mu \mathrm{mol} / \mathrm{L}$, respectively, showed no cell toxicity [49]. These concentrations are much lower than our maximum concentration tested, i.e., $1 \mathrm{~mol} / \mathrm{L}$, which does not exert any cytotoxic effect triggered by these two glycated amino acids. In the case of MG-H1, its concentration according to several studies in serum of nondiabetic patients is at $76.67 \pm 35.93 \mathrm{nmol} / \mathrm{L}$ [50] and in plasma at $109.97 \pm 46.00 \mathrm{nmol} / \mathrm{L}$ [51]. Moreover, the daily intake of CEL was calculated to be $\sim 0.01 \mathrm{mmol}$, of CML 0.015 mmol, and MG-H1 0.1 mmol. In the case of Pyrr, the intake was estimated to be around $0.08-0.16 \mathrm{mmol}$ [52]. Again, these quantities are below the maximum ones employed in this study, which do not show any harmful effect on our cell model.

Furthermore, we have not found any cytotoxicity of 3-DG in our cellular model, which agrees with another study where this 1,2-dicarbonyl compound was tested in PC12 cells and no cytotoxicity was found [53]. It has been described that the plasma concentration in type 2 diabetes patients of 3-DG is $1.37 \mu \mathrm{mol} / \mathrm{L}$, of GO $0.74 \mu \mathrm{mol} / \mathrm{L}$, and of $\mathrm{MGO} 0.31 \mu \mathrm{mol} / \mathrm{L}$ [54]. In serum of patients with chronic kidney disease, the amounts have been found to be of $1.64 \mu \mathrm{mol} / \mathrm{L}$ for 3-DG, $1.72 \mu \mathrm{mol} / \mathrm{L}$ for $\mathrm{GO}$, and $1.08 \mu \mathrm{mol} / \mathrm{L}$ for $\mathrm{MGO}$ [55]. In peritoneal dialysis fluids, 3-DGal has been detected at a concentration of $\leq 16 \mu \mathrm{mol} / \mathrm{L}$ and $3-\mathrm{DG}$ at a concentration of $\leq 7 \mu \mathrm{mol} / \mathrm{L}$ [56]. These numbers are below the concentration of these compounds from which we see effects in keratinocytes. However, the concentration of 3,4-DGE in peritoneal dialysis fluids is $9-22 \mu \mathrm{mol} / \mathrm{L}$ [57], which is an amount that already decreases cell viability in our cellular model.

Moreover, some studies using other cell types describe a reduction in cell viability of $\sim 22 \%$ with a concentration of $1 \mathrm{mmol} / \mathrm{L}$ MGO in leukocytes [58] and $1.6 \mathrm{mmol} / \mathrm{L}$ in endothelial cells [59]. MGO is found at high concentrations in Manuka honey [60]. Its cytotoxicity and its mediated $\mathrm{NF}-\kappa \mathrm{B}$ activation have been reported by several groups [61-63]. Besides, MGO has also been found to increase the phosphorylation of the MAPK family members p-JNK, p-ERK, and p-p38 and highly decrease the levels of MMP-9 and Bcl-2 [64]. MGO has also been associated with metabolism and mitochondrial function, inhibiting glycolysis and mitochondrial complex I $[65,66]$.

We found that the antioxidant NAC, a synthetic precursor of the intracellular antioxidant glutathione (GSH), can recover cell viability in a different degree upon treatment with 3-DGal, 3,4-DGE, GO, and MGO. This is in accordance with previous studies, which have shown that pretreatment with NAC improved cell viability in MGO-treated cells [67]. Furthermore, in another study, performed this time in the pancreatic beta-cell line INS-1, it was reported that cell viability decreased to $70 \%$ when cells were treated for 24 hours with $2 \mathrm{mmol} / \mathrm{L}$ MGO. However, this effect was partly recovered when cells were also incubated with $400 \mu \mathrm{mol} / \mathrm{L}$ NAC [68]. It is of notice that the concentration of NAC employed in both studies was much lower than the concentration employed in our study. Moreover, in the first study, the cell culture medium containing NAC was discarded before incubation with MGO. Besides, the concentration of MGO used in the second study in INS-1 cells was much higher than the amount we used. Nevertheless, MGO might produce cytotoxic effects at different concentrations in different cell lines, as shown by other authors [69-73]. The recovery in cell viability upon coincubation with NAC might be due to the capacity of NAC to scavenge free radicals, but it may also be considered that it forms hemithioacetals with MGO in the culture media (Figure 9).

We also saw that cells treated with these 1,2-dicarbonyls produce different ROS, being MGO, which induces a greater production of peroxides and superoxide anion in the cells. Some previous studies have identified an increase in the intracellular levels of ROS after treatment with AGEs [3436]. They found that glycated human serum albumin, rich in AGEs, induced the expression of E-selectin in the endothelial cells of HUVEC. However, when cells were preincubated with diphenyleneiodonium (DPI), an inhibitor of NADPH 


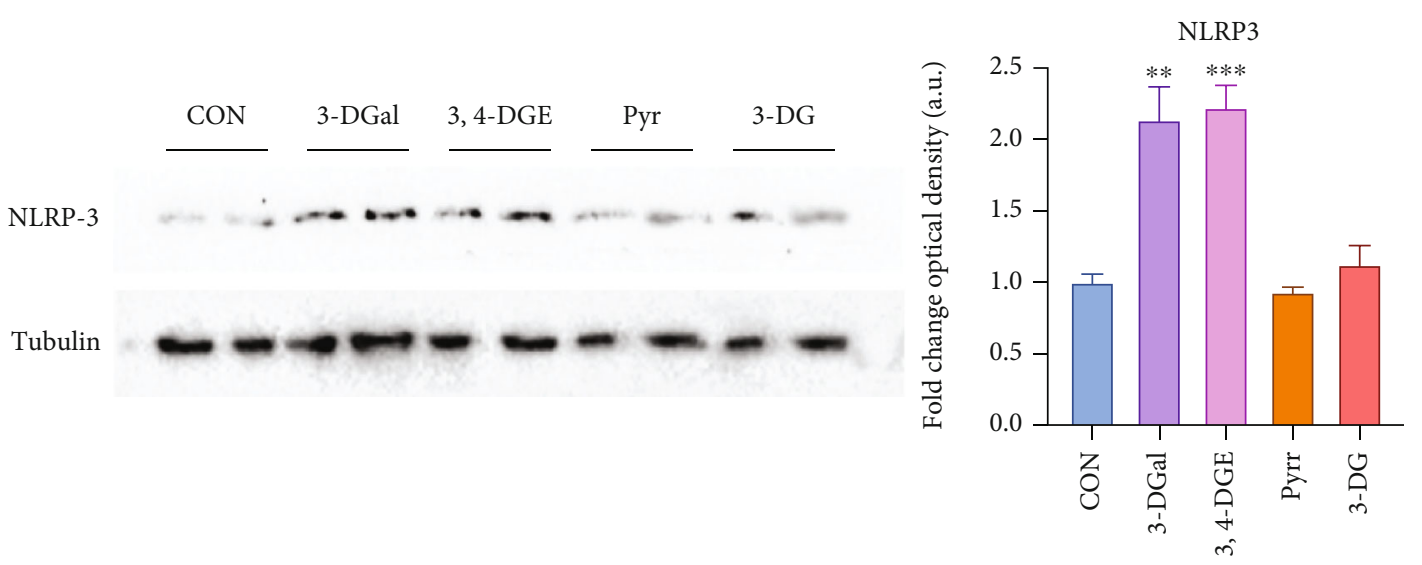

(a)
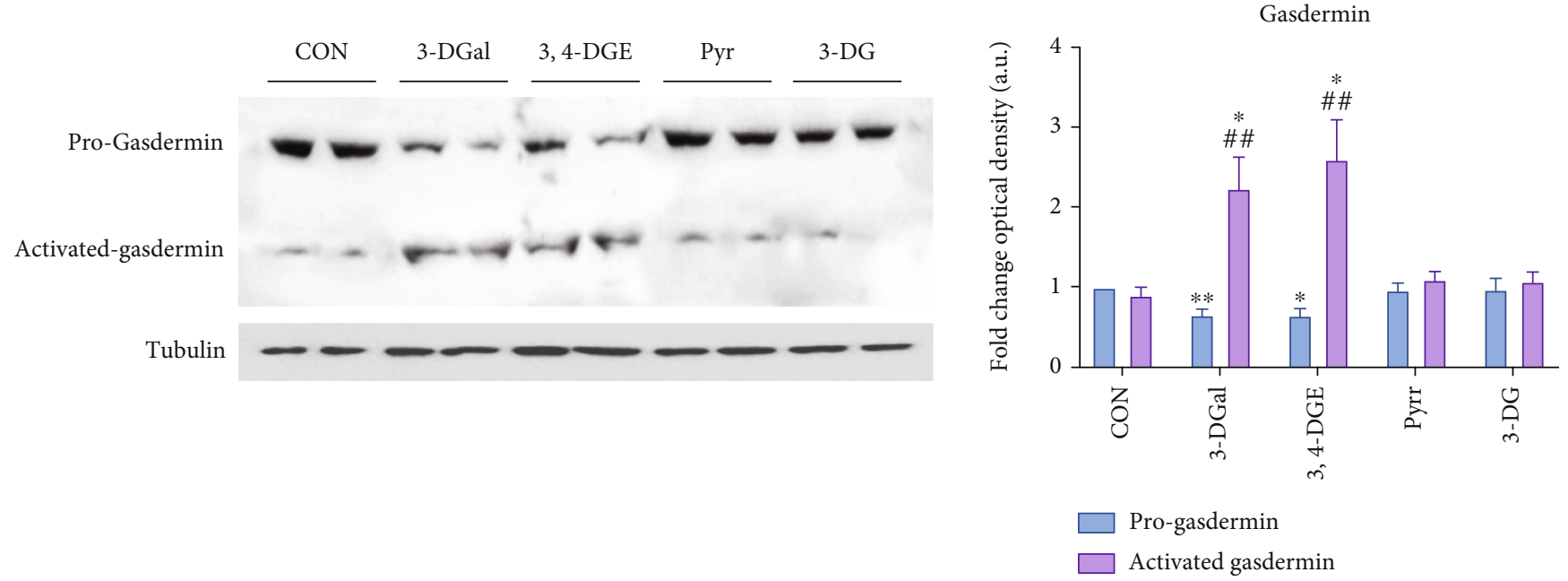

(b)

FIGURE 10: NLRP3 inflammasome and gasdermin activation upon incubation with 1,2-dicarbonyls. (a) NLRP3 inflammasome activation. A representative western blot experiment is shown. Graphic represents the production of NLRP3 as analyzed by quantification of western-blot optical density. (b) Gasdermin activation. A representative western blot experiment is shown. Graphic represents the production of progasdermin and activated gasdermin as analyzed by quantification of western blot optical density. Arbitrary 1.0 value was given to the CON group. Here, cell treatments consisted of $750 \mu \mathrm{M}$ 3-DGal, $75 \mu \mathrm{M}$ 3,4-DGE, $1 \mathrm{mM}$ Pyrr, and $1 \mathrm{mM}$ 3-DG. Results are expressed as mean $\pm \operatorname{SEM}(n=3) .{ }^{*} p<0.05 v s$. CON,${ }^{* *} p<0.01 v s$. CON, ${ }^{* * *} p<0.001 v s$. CON, ${ }^{\# \#} p<0.01$ vs. progasdermin.

oxidase, E-selectin expression was suppressed in a dosedependent manner. There was indeed an AGEs-induced production of ROS, as it was shown by an increase in $2^{\prime}, 7$ dichlorofluorescein (DCF) fluorescence signal upon cell treatment with AGEs [34]. Similar results have been reported in a cellular model of macrophages. When these cells were treated with the product of the reaction between MGO and bovine serum albumin, rich in MGO-derived AGEs, ROS production assayed by $2^{\prime}, 7^{\prime}$-dichlorofluorescein diacetate (DCFHDA) was increased. The origin of these ROS might be NADPH oxidase since, upon incubation with AGEs, the mRNA of NOX1 and NOX2 was highly increased. Moreover, ROSmediated damage to proteins, measured as protein carbonyls and advanced oxidation protein products (AOPPs), was raised as well upon incubation with AGEs. Interestingly, coincubation with pterostilbene, a plant polyphenol with antioxidant properties, decreased ROS production, NOX1 and NOX2 expression, and oxidative damage to proteins [36]. A recent study performed in human endothelial cells showed that when cells were incubated with glycated albumin, it was induced an increase in the concentration of $\mathrm{H}_{2} \mathrm{O}_{2}, \mathrm{O}_{2}{ }^{-}$, and ${ }^{\circ} \mathrm{NO}$ as well as an increase in CAT, GPX, and SOD1 activities and AOPPs production. The source of these AGEs-induced ROS proved to be the mitochondria and NADPH oxidases as tested employing myxothiazol, an inhibitor of complex III of mitochondria, and the NADPH oxidase inhibitor, apocynin. Furthermore, coincubation with a plant extract with a high polyphenol content reduced the AGEs-mediated ROS production in this cellular model [35]. Nevertheless, all of these studies employed glycated albumin as a source of AGEs, and they did not demonstrate the effect of individual compounds, while in our study, we confirm that the molecules producing cytotoxic effects in our cellular model are indeed 1,2-dicarbonyls.

In recent studies, it has been found that MGO also induces ROS production in human embryonic kidney cells [74]. In SH-SY5Y cells, it was reported an increase in $\mathrm{H}_{2} \mathrm{O}_{2}$, 
$\mathrm{O}_{2}{ }^{\bullet-}$, and ${ }^{\bullet} \mathrm{NO}$ production after incubating with MGO, which also induced lipid peroxidation, protein carbonyls and thiols, protein nitration, and DNA oxidative damage. Besides, all of these effects were partly reversed by incubation with antioxidants [75]. However, all in vitro studies where the role of single 1,2-dicarbonyls is investigated are performed employing MGO, and here, we show for the first time an increased production of ROS by 3-DGal, 3,4-DGE, and GO.

It is already studied that AGEs can produce cell death, being the apoptosis proposed mechanism in the majority of cases. However, in this work, we show that, when assayed individually, not all of the compounds exert the same effect. Indeed, we show that MGO induces apoptosis in our cellular model, as assayed using Annexin- $\mathrm{V}$ staining and an inhibitor of apoptosis. This is in agreement with some recently published works where they show apoptotic death following treatment with MGO [58, 76]. Nevertheless, when we assayed 3-DGal and 3,4-DGE, we found that, surprisingly, both 1,2-dicarbonyls do not enhance apoptosis in the cells. Moreover, keratinocytes exposed to 3-DGal and 3,4-DGE in the presence of inhibitors of death by autophagy, ferroptosis, and necroptosis were not able to preserve from death. Interestingly, these compounds were able to induce the activation of gasdermin, the protein that triggers pyroptosis, one form of programed necrosis. Thus, we propose here that ROS produced by 3-DGal and 3,4-DGE promote pyroptosis through NLRP-3 inflammasome activation [77, 78], leading to gasdermin cleavage, following formation of pores in the membrane of the cell and, thus, swelling and membrane rupture [79].

It has already been described that AGEs, by interaction with their receptor RAGE, initiate several signal transduction cascades such as NF- $\kappa \mathrm{B}$, which ultimately lead to the promotion of inflammation or apoptosis, since they produce cytokines, chemokines, and some proinflammatory molecules $[18,23,37,80]$. In this study, we show how 3-DGal and 3,4 -DGE individually activate the NF- $\kappa \mathrm{B}$ pathway for the first time. The analysis shows a significant translocation of the factor NF- $\kappa \mathrm{B}$ at the nuclear level after 3,4-DGE and 3DGal treatment. The translocation of NF- $\kappa \mathrm{B}$ causes an increased expression of the NLRP3 inflammasome. NLRP3 inflammasome appears to be overexpressed and activated after incubation with 3,4-DGE and 3-DGal. The activation of the NLRP3 inflammasome is confirmed by the presence of the $\mathrm{N}$-terminal residue of GSDMD. After oligomerization, the $N$-terminal residue of GSDMD inserts itself into the membrane, generating the transmembrane pores responsible for pyroptotic cell death. Pyroptosis may be the ROSdependent cell death mechanism implicated in reducing viability in keratinocytes exposed to 3,4-DGE and 3-DGal.

3,4-DGE is a dehydration product of 3-DG and 3-DGal, and it is the most cytotoxic compound examined in this study. 3,4-DGE contains a, $\beta, \gamma$-unsaturated $\alpha$-dicarbonyl structure, which can undergo the Michael reaction in addition to the direct reaction of the carbonyl groups. Michael reaction of 3,4-DGE with glutathione (GSH) leads to an irreversible adduct due to the depletion of GSH itself with a consequent increase in oxidative stress [81], which causes the activation of the detected signal pathways. It is interesting to note that the signaling pathway activated by 3 -DGal also appear to be the same activated by 3,4-DGE, although to have this comparable effect 3-DGal must be administered at a concentration 10 times higher than 3,4-DGE. Therefore, it is proposed that 3-DGal cytotoxicity is due to facile dehydration of the compound to 3,4-DGE, which may be the actual cytotoxic form. Furthermore, it should be noted that 3-DGal, but not its epimer 3-DG, can give such effects. The reason that 3-DG and 3-DGal exhibit two different cytotoxic behaviors may reside in the kinetics of dehydration to give 3,4DGE. In a literature report, the formation of 3,4-DGE from 3-DGal was observed to be faster than from 3-DG [82].

Finally, it is worth mentioning that the bioavailability of these compounds might vary, given their chemical differences. Membrane solubility, the presence of compound transporters, or perhaps the identification of receptormediated signaling pathways in the toxicological profile of AGEs and 1,2-dicarbonyls should be further investigated.

\section{Conclusion}

Isolated glycated amino acids and 1,2-dicarbonyls do not deliver the same biological effect in human epithelial cells. ROS production and cell death are mechanisms of cytotoxicity derived from 1,2-dicarbonyls.

\section{Abbreviations}

3,4-DGE: 3,4-Dideoxyglucosone-3-ene

3-DG: 3-Deoxyglucosone

3-DGal: 3-Deoxygalactosone

7-AAD: 7-Aminoactinomycin D

AGEs: Advanced glycation end products

AOPPs: Advanced oxidation protein products

Bcl-2: $\quad$ B-cell lymphoma 2

BSA: $\quad$ Bovine serum albumin

CAT: $\quad$ Catalase

CEL: $\quad \mathrm{N}-\varepsilon$-(carboxyethyl)lysine

CML: $\quad \mathrm{N}-\varepsilon$-(carboxymethyl)lysine

DCF: $\quad 2^{\prime}, 7$-Dichlorofluorescein

DCFH-DA: $2^{\prime}, 7^{\prime}$-Dichlorofluorescein diacetate

DHE: Dihydroethidium

DHR-123: Dihydrorhodamine 123

DMEM: Dulbecco's modified Eagle's medium

DMSO: Dimethyl sulfoxide

DPI: Diphenyleneiodonium

EDTA: Ethylenediaminetetraacetic acid

ERK1/2: $\quad$ Extracellular signal-regulated kinase 1/2

FITC: $\quad$ Fluorescein isothiocyanate

GO: $\quad$ Glyoxal

GPX: $\quad$ Glutathiones peroxidase

GSDMD: Gasdermin-D

GSH: $\quad$ Glutathione

HRP: $\quad$ Horseradish peroxidase

HUVEC: Human umbilical vein endothelial cells

$\mathrm{I} \kappa \mathrm{B} \alpha$ : Nuclear factor of kappa light polypeptide gene enhancer in B-cells inhibitor alpha

IgG: Immunoglobulin G

IKK $\beta$ : $\quad$ Inhibitor of nuclear factor kappa-B kinase subunit beta 


$\begin{array}{ll}\text { MAPK: } & \text { Mitogen-activated protein kinases } \\ \text { MG-H1: } & \text { Methylglyoxal-derived hydroimidazolone-1 } \\ \text { MGO: } & \text { Methylglyoxal } \\ \text { MMP-9: } & \text { Matrix metalloproteinase 9 } \\ \text { MTT: } & \text { 3-(4,5-Dimethylthiazol-2-yl)-2,5-diphenyltet- } \\ & \text { razolium bromide } \\ \text { NAC: } & \text { N-acetyl-cysteine } \\ \text { NADPH: } & \text { Nicotinamide adenine dinucleotide phosphate } \\ \text { NF- } \kappa \text { B: } & \text { Nuclear factor kappa-light-chain-enhancer of } \\ & \text { activated B cells } \\ \text { NLRP3: } & \text { NOD-, LRR-, and pyrin domain-containing } \\ & \text { protein 3 } \\ \text { NOX1: } & \text { NADPH oxidase 1 } \\ \text { NOX2: } & \text { NADPH oxidase 1 } \\ \text { PAGE: } & \text { Polyacrylamide gel electrophoresis } \\ \text { PBS: } & \text { Phosphate-buffered saline } \\ \text { PI: } & \text { Propidium iodide } \\ \text { PI3K: } & \text { Phosphatidylinositol 3-kinase } \\ \text { PVDF: } & \text { Polyvinylidene difluoride } \\ \text { Pyrr: } & \text { Pyrraline } \\ \text { Q-VD-OPh: } & \text { Quinoline-Val-Asp-Difluorophenoxymethyl } \\ & \text { Ketone } \\ \text { RAGE: } & \text { Receptor for AGEs } \\ \text { RNase: } & \text { Ribonuclease } \\ \text { ROS: } & \text { Reactive oxygen species } \\ \text { SOD1: } & \text { Superoxide dismutase 1 } \\ \text { SOD2: } & \text { Superoxide dismutase 2 } \\ \text { TBS-T: } & \text { Tris-buffered saline with 0.1\% Tween }{ }^{\circledR} 20 \\ & \text { Detergent. } \\ & \end{array}$

\section{Data Availability}

The data used to support the conclusions of this study are available from the corresponding authors upon request.

\section{Conflicts of Interest}

The authors declare no conflicts of interest.

\section{Acknowledgments}

We thank Rebeca Alonso (Servicio de Inmunología, Hospital Universitario Central de Asturias (HUCA)) for her kind assistance with flow cytometry. This work was supported by a grant from the European Joint Programming Initiative "A Healthy Diet for a Healthy Life" (grant ID: "SALIVAGES") Vanesa Cepas was supported by MINECO-17-PCIN-2016164RMS acknowledges a Spanish Ministry of Economy, Industry and Competitivity Grant (MINECO-17-PCIN2016-164).Thomas Henle acknowledges a German Federal Ministry for Research and Education (BMBF) grant support (grant number 01EA1703).

\section{References}

[1] M. Aragno and R. Mastrocola, "Dietary sugars and endogenous formation of advanced glycation Endproducts: Emerging Mechanisms of Disease," Nutrients, vol. 9, no. 4, p. 385, 2017.

[2] G. Vistoli, D. de Maddis, A. Cipak, N. Zarkovic, M. Carini, and G. Aldini, "Advanced glycoxidation and lipoxidation end products (AGEs and ALEs): an overview of their mechanisms of formation," Free Radical Research, vol. 47, supplement 1, pp. 3-27, 2013.

[3] H. Vlassara and J. Uribarri, "Advanced glycation end products (AGE) and diabetes: cause, effect, or both?," Current Diabetes Reports, vol. 14, no. 1, p. 453, 2014.

[4] M. W. Poulsen, R. V. Hedegaard, J. M. Andersen et al., "Advanced glycation endproducts in food and their effects on health," Food and Chemical Toxicology, vol. 60, pp. 1037, 2013.

[5] L. Cannizzaro, G. Rossoni, F. Savi et al., "Regulatory landscape of AGE-RAGE-oxidative stress axis and its modulation by PPAR $\gamma$ activation in high fructose diet-induced metabolic syndrome," Nutrition and Metabolism, vol. 14, 2017.

[6] R. Mastrocola, M. Collino, M. Rogazzo et al., "Advanced glycation end products promote hepatosteatosis by interfering with SCAP-SREBP pathway in fructose-drinking mice," Am. J. Physiol. - Gastrointest. Liver Physiol., vol. 305, no. 6, pp. G398-G407, 2013.

[7] O. Lee, W. R. Bruce, Q. Dong, J. Bruce, R. Mehta, and P. J. O'Brien, "Fructose and carbonyl metabolites as endogenous toxins," Chemico-Biological Interactions, vol. 178, no. 1-3, pp. 332-339, 2009.

[8] R. Ramasamy, S. F. Yan, and A. M. Schmidt, "Receptor for AGE (RAGE): signaling mechanisms in the pathogenesis of diabetes and its complications," Annals of the New York Academy of Sciences, vol. 1243, no. 1, pp. 88-102, 2011.

[9] C. W. Heizmann, "The mechanism by which dietary AGEs are a risk to human health is via their interaction with RAGE: arguing against the motion," Molecular Nutrition \& Food Research, vol. 51, no. 9, pp. 1116-1119, 2007.

[10] R. Ramasamy, S. F. Yan, and A. M. Schmidt, "Arguing for the motion: yes, RAGE is a receptor for advanced glycation endproducts," Molecular Nutrition \& Food Research, vol. 51, no. 9, pp. 1111-1115, 2007.

[11] B. K. Rodiño-Janeiro, B. Paradela-Dobarro, S. RaposeirasRoubín, M. González-Peteiro, J. R. González-Juanatey, and E. Álvarez, "Glycated human serum albumin induces NF- $\kappa \mathrm{B}$ activation and endothelial nitric oxide synthase uncoupling in human umbilical vein endothelial cells," Journal of Diabetes and its Complications, vol. 29, no. 8, pp. 984-992, 2015.

[12] S. D. Yan, A. M. Schmidt, G. M. Anderson et al., "Enhanced cellular oxidant stress by the interaction of advanced glycation end products with their receptors/binding proteins," The Journal of Biological Chemistry, vol. 269, no. 13, pp. 9889-9897, 1994.

[13] M.-P. Wautier, O. Chappey, S. Corda, D. M. Stern, A. M. Schmidt, and J.-L. Wautier, "Activation of NADPH oxidase by AGE links oxidant stress to altered gene expression via RAGE," American Journal of Physiology-Endocrinology and Metabolism, vol. 280, pp. E685-E694, 2001.

[14] H. E. Matheny, T. L. Deem, and J. M. Cook-Mills, "Lymphocyte migration through monolayers of endothelial cell lines involves VCAM-1 signaling via endothelial cell NADPH oxidase," Journal of Immunology, vol. 164, no. 12, pp. 65506559, 2000.

[15] H. M. Lander, J. M. Tauras, J. S. Ogiste, O. Hori, R. A. Moss, and A. M. Schmidt, "Activation of the receptor for advanced glycation end products triggers a p21 ras-dependent mitogen-activated protein kinase pathway regulated by oxidant stress," The Journal of Biological Chemistry, vol. 272, no. 28 , pp. 17810-17814, 1997. 
[16] C. Ott, K. Jacobs, E. Haucke, A. Navarrete Santos, T. Grune, and A. Simm, "Role of advanced glycation end products in cellular signaling," Redox Biology, vol. 2, pp. 411-429, 2014.

[17] J. Xie, J. D. Méndez, V. Méndez-Valenzuela, and M. M. Aguilar-Hernández, "Cellular signalling of the receptor for advanced glycation end products (RAGE)," Cellular Signalling, vol. 25, no. 11, pp. 2185-2197, 2013.

[18] M. P. Cohen, E. Shea, S. Chen, and C. W. Shearman, "Glycated albumin increases oxidative stress, activates NF- $\kappa \mathrm{B}$ and extracellular signal-regulated kinase (ERK), and stimulates erk-dependent transforming growth factor- $\beta_{1}$ production in macrophage RAW cells," The Journal of Laboratory and Clinical Medicine, vol. 141, no. 4, pp. 242-249, 2003.

[19] M. P. Wautier, P. J. Guillausseau, and J. L. Wautier, “Activation of the receptor for advanced glycation end products and consequences on health," Diabetes and Metabolic Syndrome: Clinical Research and Reviews, vol. 11, no. 4, pp. 305-309, 2017.

[20] C. Luevano-Contreras and K. Chapman-Novakofski, "Dietary advanced glycation end products and aging," Nutrients, vol. 2, no. 12, pp. 1247-1265, 2010.

[21] M. Alikhani, Z. Alikhani, C. Boyd et al., "Advanced glycation end products stimulate osteoblast apoptosis via the MAP kinase and cytosolic apoptotic pathways," Bone, vol. 40, no. 2, pp. 345-353, 2007.

[22] H. Z. Meng, W. L. Zhang, F. Liu, and M. W. Yang, "Advanced glycation end products affect osteoblast proliferation and function by modulating autophagy via the receptor of advanced glycation end products/raf protein/mitogen-activated protein kinase/extracellular signalregulated kinase kinase/extracellular," The Journal of Biological Chemistry, vol. 290, no. 47, pp. 28189-28199, 2015.

[23] J. Nevado, C. Peiró, S. Vallejo et al., "Amadori adducts activate nuclear factor- $\kappa \mathrm{B}$-related proinflammatory genes in cultured human peritoneal mesothelial cells," British Journal of Pharmacology, vol. 146, no. 2, pp. 268-279, 2005.

[24] X. Deng, W. Huang, J. Peng et al., "Irisin alleviates advanced glycation end products-induced inflammation and endothelial dysfunction via inhibiting ROS-NLRP3 inflammasome signaling," Inflammation, vol. 41, no. 1, pp. 260-275, 2018.

[25] Y. Song, Y. Wang, Y. Zhang et al., "Advanced glycation end products regulate anabolic and catabolic activities via NLRP3-inflammasome activation in human nucleus pulposus cells," Journal of Cellular and Molecular Medicine, vol. 21, no. 7, pp. 1373-1387, 2017.

[26] N. M. J. Hanssen, J. W. J. Beulens, S. Van Dieren et al., "Plasma advanced glycation end products are associated with incident cardiovascular events in individuals with type 2 diabetes: a case-cohort study with a median follow-up of 10 years (EPIC-NL)," Diabetes, vol. 64, no. 1, pp. 257-265, 2015.

[27] V. P. Singh, A. Bali, N. Singh, and A. S. Jaggi, "Advanced glycation end products and diabetic complications," Korean J. Physiol. Pharmacol., vol. 18, no. 1, pp. 1-14, 2014.

[28] J. Patche, D. Girard, A. Catan et al., "Diabetes-induced hepatic oxidative stress: a new pathogenic role for glycated albumin," Free Radical Biology \& Medicine, vol. 102, pp. 133-148, 2017.

[29] M. P. Cohen, F. N. Ziyadeh, and S. Chen, "Amadori-modified glycated serum proteins and accelerated atherosclerosis in diabetes: pathogenic and therapeutic implications," The Journal of Laboratory and Clinical Medicine, vol. 147, no. 5, pp. 211-219, 2006.
[30] L. Lu, L. J. Pu, Q. Zhang et al., "Increased glycated albumin and decreased esRAGE levels are related to angiographic severity and extent of coronary artery disease in patients with type 2 diabetes," Atherosclerosis, vol. 206, no. 2, pp. 540-545, 2009.

[31] Y. Kumeda, M. Inaba, S. Shoji et al., "Significant correlation of glycated albumin, but not glycated haemoglobin, with arterial stiffening in haemodialysis patients with type 2 diabetes," Clinical Endocrinology, vol. 69, no. 4, pp. 556-561, 2008.

[32] D. S. Fosmark, P. A. Torjesen, B. K. Kilhovd et al., "Increased serum levels of the specific advanced glycation end product methylglyoxal-derived hydroimidazolone are associated with retinopathy in patients with type 2 diabetes mellitus," Metabolism, vol. 55, no. 2, pp. 232-236, 2006.

[33] Y. Fukushima, H. Daida, T. Morimoto et al., "Relationship between advanced glycation end products and plaque progression in patients with acute coronary syndrome: the JAPANACS sub-study," Cardiovascular Diabetology, vol. 12, no. 1, p. 5, 2013.

[34] K. Higai, A. Shimamura, and K. Matsumoto, "Amadori-modified glycated albumin predominantly induces E-selectin expression on human umbilical vein endothelial cells through NADPH oxidase activation," Clinica Chimica Acta, vol. 367, no. 1-2, pp. 137-143, 2006.

[35] A. Dobi, S. B. Bravo, B. Veeren et al., "Advanced glycation endproducts disrupt human endothelial cells redox homeostasis: new insights into reactive oxygen species production," Free Radical Research, vol. 53, no. 2, pp. 150-169, 2019.

[36] W. Yu, X. Hu, and M. Wang, "Pterostilbene inhibited advanced glycation end products (AGEs)-induced oxidative stress and inflammation by regulation of RAGE/MAPK/NF$\kappa \mathrm{B}$ in RAW264.7 cells," Journal of Functional Foods, vol. 40, pp. 272-279, 2018.

[37] M. Zhang, A. L. Kho, N. Anilkumar et al., "Glycated proteins stimulate reactive oxygen species production in cardiac myocytes," Circulation, vol. 113, no. 9, pp. 1235-1243, 2006.

[38] X. L. Wang, T. Yu, Q. C. Yan et al., "AGEs promote oxidative stress and induce apoptosis in retinal pigmented epithelium cells RAGE-dependently," Journal of Molecular Neuroscience, vol. 56, no. 2, pp. 449-460, 2015.

[39] F. Boyer, J. B. Vidot, A. G. Dubourg, P. Rondeau, M. F. Essop, and E. Bourdon, "Oxidative stress and adipocyte biology: focus on the role of AGEs," Oxidative Medicine and Cellular Longevity, vol. 2015, Article ID 534873, 9 pages, 2015.

[40] M. Hellwig, J. Degen, and T. Henle, "3-deoxygalactosone, a 'new' 1,2-dicarbonyl compound in milk products," Journal of Agricultural and Food Chemistry, vol. 58, no. 19, pp. 1075210760, 2010.

[41] M. Hellwig, A. Nobis, S. Witte, and T. Henle, "Occurrence of (Z)-3,4-dideoxyglucoson-3-ene in different types of beer and malt beer as a result of 3-deoxyhexosone interconversion," Journal of Agricultural and Food Chemistry, vol. 64, no. 13, pp. 2746-2753, 2016.

[42] M. Hellwig, S. Geissler, A. Peto, I. Knütter, M. Brandsch, and T. Henle, "Transport of free and peptide-bound pyrraline at intestinal and renal epithelial cells," Journal of Agricultural and Food Chemistry, vol. 57, no. 14, pp. 6474-6480, 2009.

[43] T. Henle and A. Bachmann, "Synthesis of pyrraline reference material," Zeitschrift für Lebensmittel-Untersuchung und -Forschung, vol. 202, no. 1, pp. 72-74, 1996.

[44] M. Hellwig, S. Geissler, R. Matthes et al., "Transport of free and peptide-bound glycated amino acids: synthesis, transepithelial 
flux at Caco-2 cell monolayers, and interaction with apical membrane transport proteins," Chembiochem, vol. 12, no. 8 , pp. 1270-1279, 2011.

[45] M. B. Hansen, S. E. Nielsen, and K. Berg, "Re-examination and further development of a precise and rapid dye method for measuring cell growth/cell kill," Journal of Immunological Methods, vol. 119, no. 2, pp. 203-210, 1989.

[46] M. M. Bradford, "A rapid and sensitive method for the quantitation of microgram quantities of protein utilizing the principle of protein-dye binding," Analytical Biochemistry, vol. 72, no. 1-2, pp. 248-254, 1976.

[47] M. L. M. Lieuw-A-Fa, V. W. M. van Hinsbergh, T. Teerlink et al., "Increased levels of $\mathrm{N}$-(carboxymethyl)lysine and $\mathrm{N}$ (carboxyethyl)lysine in type 1 diabetic patients with impaired renal function: correlation with markers of endothelial dysfunction," Nephrology, Dialysis, Transplantation, vol. 19, no. 3, pp. 631-636, 2004.

[48] S. Agalou, N. Ahmed, R. Babaei-Jadidi, A. Dawnay, and P. J. Thornalley, "Profound mishandling of protein glycation degradation products in uremia and dialysis," J. Am. Soc. Nephrol., vol. 16, no. 5, pp. 1471-1485, 2005.

[49] J. Zhu, K. Yang, Y. Jing et al., "The effects of low-dose nepsilon-(carboxymethyl)lysine (CML) and nepsilon-(carboxyethyl)lysine (CEL), two main glycation free adducts considered as potential uremic toxins, on endothelial progenitor cell function," Cardiovascular Diabetology, vol. 11, no. 1, p. 90, 2012.

[50] T. Okura, E. Ueta, R. Nakamura et al., "High serum advanced glycation end products are associated with decreased insulin secretion in patients with type 2 diabetes: a brief report," Journal Diabetes Research, vol. 2017, no. 5139750, pp. 1-7, 2017.

[51] P. J. THORNALLEY, S. BATTAH, N. AHMED et al., "Quantitative screening of advanced glycation endproducts in cellular and extracellular proteins by tandem mass spectrometry," The Biochemical Journal, vol. 375, no. 3, pp. 581-592, 2003.

[52] M. Hellwig and T. Henle, "Quantification of the Maillard reaction product 6-(2-formyl-1-pyrrolyl)-L-norleucine (formyline) in food," European Food Research and Technology, vol. 235, no. 1, pp. 99-106, 2012.

[53] K. Suzuki, Y. H. Koh, H. Mizuno, R. Hamaoka, and N. Taniguchi, "Overexpression of aldehyde reductase protects PC12 cells from the cytotoxicity of methylglyoxal or 3-deoxyglucosone," Journal of Biochemistry, vol. 123, no. 2, pp. 353357, 1998.

[54] N. M. J. Hanssen, J. Westerink, J. L. J. M. Scheijen et al., "Higher plasma methylglyoxal levels are associated with incident cardiovascular disease and mortality in individuals with type 2 diabetes," Diabetes Care, vol. 41, no. 8, pp. 1689-1695, 2018.

[55] R. J. H. Martens, N. J. H. Broers, B. Canaud et al., "Relations of advanced glycation endproducts and dicarbonyls with endothelial dysfunction and low-grade inflammation in individuals with end-stage renal disease in the transition to renal replacement therapy: a cross-sectional observational study," PLoS One, vol. 14, no. 8, p. e0221058, 2019.

[56] S. Gensberger-Reigl, J. Huppert, and M. Pischetsrieder, "Quantification of reactive carbonyl compounds in icodextrin-based peritoneal dialysis fluids by combined UHPLC-DAD and -MS/MS detection," Journal of Pharmaceutical and Biomedical Analysis, vol. 118, pp. 132-138, 2016.

[57] T. Linden, A. Cohen, R. Deppisch, P. Kjellstrand, and A. Wieslander, "3,4-Dideoxyglucosone-3-ene (3,4-DGE): a cytotoxic glucose degradation product in fluids for peritoneal dialysis," Kidney International, vol. 62, no. 2, pp. 697-703, 2002.

[58] A. de Souza Prestes, M. M. dos Santos, A. Ecker et al., "Methylglyoxal disturbs the expression of antioxidant, apoptotic and glycation responsive genes and triggers programmed cell death in human leukocytes," Toxicology in Vitro, vol. 55, pp. 33-42, 2019.

[59] J. D. Braun, D. O. Pastene, A. Breedijk et al., "Methylglyoxal down-regulates the expression of cell cycle associated genes and activates the p53 pathway in human umbilical vein endothelial cells," Scientific Reports, vol. 9, no. 1, p. 1152, 2019.

[60] E. Mavric, S. Wittmann, G. Barth, and T. Henle, "Identification and quantification of methylglyoxal as the dominant antibacterial constituent of Manuka (Leptospermum scoparium) honeys from New Zealand," Molecular Nutrition \& Food Research, vol. 52, no. 4, pp. 483-489, 2008.

[61] M. Paul-Samojedny, B. Łasut, A. Pudełko et al., "Methylglyoxal (MGO) inhibits proliferation and induces cell death of human glioblastoma multiforme T98G and U87MG cells," Biomedicine \& Pharmacotherapy, vol. 80, pp. 236-243, 2016.

[62] C. Antognelli, L. Mezzasoma, K. Fettucciari, and V. N. Talesa, "A novel mechanism of methylglyoxal cytotoxicity in prostate cancer cells," The International Journal of Biochemistry \& Cell Biology, vol. 45, no. 4, pp. 836-844, 2013.

[63] S. Chakraborty, K. Karmakar, and D. Chakravortty, "Cells producing their own nemesis: understanding methylglyoxal metabolism," IUBMB Life, vol. 66, no. 10, pp. 667-678, 2014.

[64] Y. Guo, Y. Zhang, X. Yang et al., "Effects of methylglyoxal and glyoxalase I inhibition on breast cancer cells proliferation, invasion, and apoptosis through modulation of MAPKs, MMP9, and Bcl-2," Cancer Biology \& Therapy, vol. 17, no. 2, pp. 169-180, 2016.

[65] S. Biswas, M. Ray, S. Misra, D. P. Dutta, and S. Ray, "Selective inhibition of mitochondrial respiration and glycolysis in human leukaemic leucocytes by methylglyoxal," The Biochemical Journal, vol. 323, no. 2, pp. 343-348, 1997.

[66] A. Ghosh, S. Bera, S. Ray, T. Banerjee, and M. Ray, "Methylglyoxal induces mitochondria-dependent apoptosis in sarcoma," The Biochemist, vol. 76, pp. 1164-1171, 2011.

[67] C. T. Yang, F. H. Meng, L. Chen et al., "Inhibition of methylglyoxal-induced AGEs/RAGE expression contributes to dermal protection by N-acetyl-L-cysteine," Cellular Physiology and Biochemistry, vol. 41, no. 2, pp. 742-754, 2017.

[68] C. Liu, Y. Huang, Y. Zhang, X. Chen, X. Kong, and Y. Dong, "Intracellular methylglyoxal induces oxidative damage to pancreatic beta cell line INS- 1 cell through Ire $1 \alpha$-JNK and mitochondrial apoptotic pathway," Free Radical Research, vol. 51, no. 4, pp. 337-350, 2017.

[69] F. M. Ayoub, R. E. Allen, and P. J. Thornalley, "Inhibition of proliferation of human leukaemia 60 cells by methylglyoxal in vitro," Leukemia Research, vol. 17, no. 5, pp. 397-401, 1993.

[70] W. B. Bair 3rd, C. M. Cabello, K. Uchida, A. S. Bause, and G. T. Wondrak, "GLO1 overexpression in human malignant melanoma," Melanoma Research, vol. 20, no. 2, pp. 85-96, 2010.

[71] A. P. Wieslander, A. H. G. Andrén, C. Nilsson-Thorell, N. Muscalu, P. T. T. Kjellstrand, and B. Rippe, "Are aldehydes in heat-sterilized peritoneal Dialysis fluids Toxicin vitro?," Peritoneal Dialysis International, vol. 15, no. 4, pp. 348-352, 1995.

[72] S. Davidson, D. Milanesa, C. Mallouh, M. Choudhury, H. Tazaki, and S. Konno, "A possible regulatory role of 
glyoxalase I in cell viability of human prostate cancer," Urological Research, vol. 30, no. 2, pp. 116-121, 2002.

[73] X. Durando, E. Thivat, M. C. Farges et al., "Optimal methionine-free diet duration for nitrourea treatment: a phase I clinical trial," Nutrition and Cancer, vol. 60, no. 1, pp. 23-30, 2008.

[74] J. H. Lee, L. Subedi, and S. Y. Kim, "Effect of cysteine on methylglyoxal-induced renal damage in mesangial cells," Cells, vol. 9, no. 1, p. 234, 2020.

[75] M. R. de Oliveira, I. C. C. de Souza, and C. R. Fürstenau, "Mitochondrial protection promoted by the coffee diterpene kahweol in methylglyoxal-treated human neuroblastoma SHSY5Y cells," Neurotoxicity Research, vol. 37, no. 1, pp. 100$110,2020$.

[76] F. Nan, G. Sun, W. Xie et al., "Ginsenoside Rb1 mitigates oxidative stress and apoptosis induced by methylglyoxal in $\mathrm{SH}$ SY5Y cells via the PI3K/Akt pathway," Molecular and Cellular Probes, vol. 48, p. 101469, 2019.

[77] J. M. Abais, M. Xia, Y. Zhang, K. M. Boini, and P. L. Li, "Redox regulation of NLRP3 inflammasomes: ROS as trigger or effector?," Antioxidants Redox Signal, vol. 22, no. 13, pp. 11111129, 2015.

[78] F. Martinon, "Signaling by ROS drives inflammasome activation," European Journal of Immunology, vol. 40, no. 3, pp. 616-619, 2010.

[79] S. B. Kovacs and E. A. Miao, "Gasdermins: effectors of pyroptosis," Trends in Cell Biology, vol. 27, no. 9, pp. 673-684, 2017.

[80] Q. Zhang, M. J. Lenardo, and D. Baltimore, "30 years of NF$\kappa \mathrm{B}$ : A blossoming of relevance to human pathobiology," Cell, vol. 168, no. 1-2, pp. 37-57, 2017.

[81] T. Yamamoto, T. Tomo, E. Okabe, S. Namoto, K. Suzuki, and Y. Hirao, "Glutathione depletion as a mechanism of 3,4dideoxyglucosone-3-ene-induced cytotoxicity in human peritoneal mesothelial cells: role in biocompatibility of peritoneal dialysis fluids," Nephrology, Dialysis, Transplantation, vol. 24, no. 5, pp. 1436-1442, 2009.

[82] S. Mittelmaier, M. Fünfrocken, D. Fenn, and M. Pischetsrieder, "3-Deoxygalactosone, a new glucose degradation product in peritoneal dialysis fluids: identification, quantification by HPLC/DAD/MSMS and its pathway of formation," Analytical and Bioanalytical Chemistry, vol. 399, no. 4, pp. 1689-1697, 2011. 